\title{
South Pacific Decadal Climate Variability and Potential Predictability
}

\author{
JIALE LOU \\ Institute for Marine and Antarctic Studies, and ARC Centre of Excellence for Climate System Science, \\ University of Tasmania, Hobart, Tasmania, Australia \\ NEIL J. HOLBROOK \\ Institute for Marine and Antarctic Studies, and ARC Centre of Excellence for Climate Extremes, \\ University of Tasmania, Hobart, Tasmania, Australia \\ TERENCE J. O'KANE \\ CSIRO Oceans and Atmosphere, Hobart, Tasmania, Australia
}

(Manuscript received 25 April 2018, in final form 17 May 2019)

\begin{abstract}
The South Pacific decadal oscillation (SPDO) characterizes the Southern Hemisphere contribution to the Pacific-wide interdecadal Pacific oscillation (IPO) and is analogous to the Pacific decadal oscillation (PDO) centered in the North Pacific. In this study, upper ocean variability and potential predictability of the SPDO is examined in HadISST data and an atmosphere-forced ocean general circulation model. The potential predictability of the IPO-related variability is investigated in terms of both the fractional contribution made by the decadal component in the South, tropical and North Pacific Oceans and in terms of a doubly integrated first-order autoregressive (AR1) model. Despite explaining a smaller fraction of the total variance, we find larger potential predictability of the SPDO relative to the PDO. We identify distinct local drivers in the western subtropical South Pacific, where nonlinear baroclinic Rossby wave-topographic interactions act to low-pass filter decadal variability. In particular, we show that the Kermadec Ridge in the southwest Pacific enhances the decadal signature more prominently than anywhere else in the Pacific basin. Applying the doubly integrated AR1 model, we demonstrate that variability associated with the Pacific-South American pattern is a critically important atmospheric driver of the SPDO via a reddening process analogous to the relationship between the Aleutian low and PDO in the North Pacific—albeit that the relationship in the South Pacific appears to be even stronger. Our results point to the largely unrecognized importance of South Pacific processes as a key source of decadal variability and predictability.
\end{abstract}

\section{Introduction}

In line with the great volume of the Southern Hemisphere (SH) oceans, the South Pacific Ocean exhibits prominent decadal climate variability (e.g., Reason 2000). That said, our understanding of Pacific and in particular South Pacific decadal variability and predictability has been limited, despite this being an emerging area of substantial interest and active research (Meehl et al. 2014; Holbrook et al. 2014; Power et al. 2017). The lack of consistent long-term observations has in part led to less attention being drawn to the South Pacific. In recognition of the significant role that the Southern Oceans, and in particular the South Pacific,

Corresponding author: Jiale Lou, jiale.lou@utas.edu.au play in the regional and global climate combined with the rapid development of the Argo observing system, there is now intense interest in the variability and dynamics of this region. Analogous to the approach used to define the Pacific decadal oscillation (PDO; Mantua et al. 1997) in the North Pacific, Shakun and Shaman (2009) recently introduced the $\mathrm{SH}$ equivalent as the leading empirical orthogonal function (EOF) of sea surface temperature anomalies (SSTA) over the South Pacific poleward of $20^{\circ} \mathrm{S}$. This feature was later named the South Pacific decadal oscillation (SPDO; e.g., Chen and Wallace 2015). Shakun and Shaman (2009) found that the PDO and SPDO in the North and South Pacific are qualitatively very similar on interdecadal time scales. In addition, Power et al. (1999) and Folland et al. (2002) introduced the interdecadal Pacific oscillation 
(IPO) in order to characterize the decadal variability over the entire Pacific basin.

Many studies show that the IPO, PDO, and SPDO are closely correlated with El Niño-Southern Oscillation (ENSO) at low frequencies and largely characterize the decadal to interdecadal climate variability across the Pacific Ocean. Newman et al. (2016) examined the temporal correlations between the sea surface temperature (SST) variability of the PDO, the IPO, and the SPDO finding significant correlations between the low-pass-filtered time series of the IPO with the SPDO $(r=0.82)$ and the PDO $(r=0.74)$. However, studies on decadal variability in the South Pacific (i.e., SPDO) are lacking and most previous studies have focused on the SST variability (see, e.g., Shakun and Shaman 2009), but not the subsurface, nor the potential mechanisms and predictability of the SPDO.

In the North Pacific, it has been recognized that the PDO is not simply a single physical mode but instead largely represents the combination of different processes operating on different time scales (e.g., Newman et al. 2016; Liu and Di Lorenzo 2018). These multiscale processes include white noise atmospheric forcing (Hasselmann 1976; Di Lorenzo and Ohman 2013), ENSO teleconnections (Leathers et al. 1991; Newman et al. 2003; White et al. 2003), and fundamental ocean dynamical processes (Deser et al. 2003; Capotondi et al. 2005; Schneider and Cornuelle 2005; McGregor et al. 2007; Lyu et al. 2017). However, even a cursory reading of the literature indicates a considerable degree of uncertainty as to the relative importance of any one dynamic mechanism being the dominant cause of the observed interdecadal variability over the midlatitude Pacific. In the present study, we complement understanding of the PDO outlined in a recent review by Liu and Di Lorenzo (2018), and that draws on the revisited analysis by Newman et al. (2016), by analyzing the role of stochastic surface forcing and internal ocean dynamics on the SPDO.

Relative to the extensive literature on the PDO, the SPDO has been less widely discussed. One possible reason is that the PDO dominates the interdecadal time scales while the surface variability of the SPDO exhibits more interannual to quasi-decadal features (Chen and Wallace 2015; Newman et al. 2016). Another possible reason is that observed South Pacific Ocean data are sparse (Basher and Zheng 1998) relative to those in the North Pacific.

Motivated by similarities with the spatiotemporal characteristics of the PDO (Liu and Di Lorenzo 2018), and cognizant of the fact that the SPDO integrates multiple dynamics of the atmospheric forcing, ENSO teleconnections, and oceanic processes in the $\mathrm{SH}$, in this study, we show the requisite atmospheric stochastic forcing in combination with tropical teleconnections and oceanic dynamics required in combination to generate the SPDO.

Although the SPDO is much less well understood, there is a growing body of evidence that highlights the importance of different dynamics over the South Pacific. For example, from an atmosphere perspective, the Pacific-South American pattern 1 (PSA1), which was defined as the second leading mode of the $500-\mathrm{hPa}$ geopotential height (Z500) over the SH (Lau et al. 1994; Mo 2000; O'Kane et al. 2017), is characterized by multiple time scales from intraseasonal to decadal (Kiladis and Mo 1998). Mo (2000) showed that the atmospheric PSA1 is highly correlated to the ENSO-like SST pattern on interannual time scales. O'Kane et al. (2017) identified the influence of tropical convection on the thermal wind as the source of this correlation.

From the ocean perspective, some studies also emphasize the importance of oceanic dynamics to decadal variability in the South Pacific (Holbrook and Bindoff 1997; Linsley et al. 2000; Power and Colman 2006; McGregor et al. 2007; O'Kane et al. 2014b; Sloyan and O'Kane 2015, Chung et al. 2017). For example, in a numerical modeling study, Holbrook et al. (2011) showed that long baroclinic Rossby waves provided an important mechanism for modulating East Australian Current (EAC) transports and corresponding observed sea level variations in Sydney Harbour on ENSO to decadal time scales. Using ocean state estimates, Hill et al. (2011) further showed decadal scale changes in EAC intensity in opposition to that in the Tasman Front.

Aside from long baroclinic Rossby waves, O'Kane et al. (2014b) showed that nonlinear instabilities in ocean storm tracks are key to the multiscale properties of Rossby waves and further enhance decadal variability over the South Pacific. Sloyan and O'Kane (2015) concluded that internal ocean dynamics are important drivers of decadal variability in the Tasman Sea, and that the stability of the EAC is linked, via the South Caledonian jet, to the stability of the pan-basin subtropical South Pacific Ocean "storm track." Travis and Qiu (2017) argued that changes in oceanic stratification and vertical shear of horizontal velocities can cause decadal variability of baroclinic instability in the subtropical countercurrent (STCC) region over the South Pacific. Utilizing an ocean general circulation model, Rieck et al. (2018) also show that the STCC region (i.e., $25^{\circ}$ $33^{\circ} \mathrm{S}, 153^{\circ}-175^{\circ} \mathrm{W}$ ) exhibits significant decadal baroclinic instability.

Given the importance of decadal climate variability and gaps in our current knowledge (Holbrook et al. 2014), understanding the mechanisms and predictability 
of the IPO-related variability therefore has great societal value. Some studies argue that long-term climate predictability is limited by the effects of high-frequency processes (Boer 2004; Power and Colman 2006; Frederiksen et al. 2016), while others argue that the main limitation is from the growth of initial errors due to flow instabilities (e.g., Griffies and Bryan 1997; Boer 2000; Yang et al. 2008; Branstator et al. 2012).

Because of different perspectives, predictability can take different forms - for example, the terms "diagnostic/ potential predictability" and "prognostic/practical predictability" are referred to separately for distinction. The former is more a statistical concept and provides an estimate of the upper limit to predictive skill assuming a perfect model, and often termed as the ratio of the variance of the potentially predictable component relative to the variance of the total variability (e.g., Boer 2000; Frederiksen et al. 2016; Lou et al. 2017). Predictability is "potential" in the sense that the presence of appreciable long time scale variability is not directly indicative so that it may be skillfully predicted (Kirtman et al. 2013). Nevertheless, it provides a convenient and simple measure of the relative importance of decadal variability (Liu and Di Lorenzo 2018). The latter is investigated by perturbing initial conditions in numerical simulations to estimate the rate of separation of initially close trajectories about the climate attractor (Yang et al. 2008; Meehl et al. 2009, 2010; Meehl and Teng 2012; Meehl et al. 2014; Nadiga and O'Kane 2017). However, the period for which climate model simulations can accurately track the nonlinear trajectory of the climate is hampered by an insufficient record length of subsurface ocean observations with which to constrain the models, the computational cost of ensemble coupled data assimilation, and the large model biases in the current generation of general circulation models.

While many studies on potential predictability exist in the literature, most have a tropics-North Pacific focus. Notable studies include those on climate variability (Newman et al. 2003; Chen et al. 2004; Alexander et al. 2008), sea surface temperature (Newman 2007; Frederiksen et al. 2016), atmospheric circulation (Lou et al. 2017), precipitation (Ying et al. 2018), ocean heat content ( $\mathrm{Li}$ et al. 2017), and ocean subsurface temperatures (Power and Colman 2006), to give only a few examples. In addition, first-order autoregressive (AR1) models (Boer 2000; Newman et al. 2003), linear inverse models (Newman 2007; Alexander et al. 2008; Newman et al. 2011, 2016), decadal decomposition methods (Frederiksen et al. 2016; Lou et al. 2017; Ying et al. 2018), and other statistical or physical models have also been applied to quantify the potential predictability.
Frankignoul and Hasselmann (1977) introduced the AR1 model and applied it to investigate the North Pacific air-sea system. AR1-based models are linear stochastic models driven by white-noise forcing where the low-frequency variability is simply associated with the persistence of itself with some empirically determined decorrelation time scale. The AR1 model can be applied in a number of ways, for example, including remote forcing of ENSO as a noise term (e.g., Newman et al. 2003; Power and Colman 2006; Liu 2012) or by repeat (double) integration of AR1 model(s) (Di Lorenzo and Ohman 2013).

In the present study, we apply various decomposition methods, including 1) the fractional contribution made by the decadal component in the South Pacific, tropical Pacific, and North Pacific Oceans, respectively; and 2) the doubly integrated AR1 model to investigate how atmospheric variability, sea surface temperature variability and subsurface ocean temperature variability combine to produce the SPDO. We examine model simulations and observational datasets to better explore and analyze the relationship between surface and subsurface Pacific Ocean temperature variability and potential predictability.

This paper is organized as follows. The data and model details used in this study are described in section 2. Next, we compare the surface (section 3 ) and subsurface (section 4) temperature variability-where observed SST (HadISST) and simulated ocean temperature variability and vertical structure are based on an atmosphere-forced ocean model (previously described in section 2). In section 5 we undertake a sectoral correlation analysis of decadal variability over the Pacific basin. The role of atmospheric forcing in generating the ocean response is examined in section 6. Our discussion and conclusions are given in section 7 .

\section{Data and model}

This study uses observed monthly SST data from HadISST.1.1 on a $1^{\circ} \times 1^{\circ}$ grid, covering the period from 1870 to 2017 (Rayner et al. 2003) and available from https://www.metoffice.gov.uk/hadobs/hadisst/data/ download.html. For the purposes of our analysis, the HadISST.1.1 SST data have been regridded to a $2.5^{\circ} \times$ $2.5^{\circ}$ grid.

The model used is the Australian Community Climate and Earth-System Simulator-Ocean (ACCESS-O) configuration of the GFDL MOM4p1 ocean-ice code (Delworth et al. 2006). The model configuration is described in O'Kane et al. (2014b). For comparison, the original $360 \times 300$ tripolar ACCESS-O ocean model grid has been interpolated to a regular $2.5^{\circ} \times 2.5^{\circ}$ grid in 
this study. ACCESS-O has 50 model levels in the vertical covering $0-6000 \mathrm{~m}$ with depth intervals ranging from $10 \mathrm{~m}$ in the upper ocean $(0-200 \mathrm{~m})$ to about $333 \mathrm{~m}$ for the abyssal ocean (O'Kane et al. 2014a; 2014b). ACCESS-O is forced by observed atmospheric fields from the Coordinated Ocean-Ice Reference Experiments (COREs; 1948-2007) (Griffies et al. 2009).

At the same time, we also use monthly mean sea level pressure (SLP) and Z500 reanalysis data over the period 1948-2007 in this study, taken from the National Centers for Environmental Prediction-National Center for Atmospheric Research (NCEP-NCAR) and available at https://www.esrl.noaa.gov/psd/data/gridded/data. ncep.reanalysis.surface.html and https://www.esrl.noaa.gov/ $\mathrm{psd} / \mathrm{data} / \mathrm{gridded} /$ data.ncep.reanalysis.pressure.html, respectively. The SLP and Z500 data were analyzed at the data-provided $2.5^{\circ} \times 2.5^{\circ}$ resolution.

In performing EOF and other statistical analyses upon the variables, we make use of the detrended and anomalous monthly data. That is, all the observed and simulated data were linearly detrended at each grid point first. Then, the seasonal climatology was removed from the monthly data at each grid point to derive the anomalies. The principal component (PC) time series derived from the EOF analysis is then regarded as the relevant climate index.

In addition, we refer to some previous published climate indices in this paper. Most are predicated upon the SST field. We also apply the same definition to the integrated subsurface ocean temperature field, which we will discuss in section 4a. Abbreviations, brief definitions and references for these climate indices are listed in Table 1.

The significance of the correlation and cross-correlation coefficients has been performed following the approach of Davis (1976). This takes account of the effective number of degrees of freedom due to serial correlation, and a simple $t$ statistic was applied to assess whether the two time series were significantly correlated.

\section{Observed and simulated SST variability}

Taking the available CORE atmospheric forcing data into account, the model was run for 60 years from 1948 to 2007. The EOF analysis using the 1948-2007 HadISST and ACCESS-O data has been performed for the North Pacific, tropical Pacific, and South Pacific, where the leading modes represent the PDO, ENSO, and SPDO, respectively.

Figure 1 shows the resulting EOF spatial patterns of SST in each of the three constituent regions. The simulated SST patterns (Figs. 1d-f) are similar to the observed SST patterns (Figs. 1a-c), as are the relative
TABLE 1. Abbreviations and definitions of the climate indices referred to in this study.

\begin{tabular}{|c|c|}
\hline Abbreviation & Definition \\
\hline GL-PC1 & $\begin{array}{l}\text { PC1 of near-global SST anomalies (SSTA; } \\
\left.70^{\circ} \mathrm{S}-70^{\circ} \mathrm{N}\right)\end{array}$ \\
\hline Niño-3.4 & $\begin{array}{l}\text { The area-averaged SSTA over the region } 5^{\circ} \mathrm{N}-5^{\circ} \mathrm{S} \\
\text { and } 170^{\circ}-120^{\circ} \mathrm{W}\end{array}$ \\
\hline TPI & $\begin{array}{l}\text { Tripole index (Henley et al. } 2015) \text {, which is } \\
\text { defined as the difference between the average } \\
\text { SSTA over the central equatorial Pacific } \\
\left(10^{\circ} \mathrm{S}-10^{\circ} \mathrm{N}, 170^{\circ} \mathrm{E}-90^{\circ} \mathrm{W}\right) \text { and the average } \\
\text { of the SSTA in the northwest }\left(25^{\circ}-45^{\circ} \mathrm{N},\right. \\
\left.140^{\circ} \mathrm{E}-145^{\circ} \mathrm{W}\right) \text { and southwest Pacific } \\
\left(50^{\circ}-15^{\circ} \mathrm{S}, 150^{\circ} \mathrm{E}-160^{\circ} \mathrm{W}\right)\end{array}$ \\
\hline NP-PC1 & $\begin{array}{l}\text { PC1 of North Pacific SSTA poleward of } 20^{\circ} \mathrm{N} \\
\text { (Mantua et al. 1997), which is used to represent } \\
\text { the time evolution of PDO }\end{array}$ \\
\hline TP-PC1 & $\begin{array}{l}\mathrm{PC} 1 \text { of tropical Pacific }\left(20^{\circ} \mathrm{S}-20^{\circ} \mathrm{N}\right) \mathrm{SSTA} \text {, which } \\
\text { is used to represent the time evolution of } \\
\text { ENSO }\end{array}$ \\
\hline SP-PC1 & $\begin{array}{l}\text { PC1 of South Pacific SSTA poleward of } 20^{\circ} \mathrm{S} \\
\text { (Chen and Wallace 2015), which is used to } \\
\text { represent the time evolution of SPDO }\end{array}$ \\
\hline P-PC1 & $\begin{array}{l}\mathrm{PC} 1 \text { of entire Pacific SSTA }\left(70^{\circ} \mathrm{S}-70^{\circ} \mathrm{N}\right. \\
\left.120^{\circ} \mathrm{E}-70^{\circ} \mathrm{W}\right)\end{array}$ \\
\hline NPI & $\begin{array}{l}\text { North Pacific index (Trenberth and Hurrell } \\
1994 \text { ), which is used to represent the Aleutian } \\
\text { low and defined as the area averaged SLP } \\
\text { anomalies over the region } 30^{\circ}-65^{\circ} \mathrm{N}, \\
160^{\circ} \mathrm{E}-140^{\circ} \mathrm{W}\end{array}$ \\
\hline PSA1 & $\begin{array}{l}\text { Pacific-South American pattern } 1 \text { (O'Kane et al. } \\
\text { 2017), which is defined as PC2 of Z500 } \\
\text { anomalies over the Southern Hemisphere }\end{array}$ \\
\hline
\end{tabular}

explained variances, a clear demonstration that the model can adequately capture the spatial features of those modes. Although the EOF analysis was restricted to each of these three constituent regions where the PDO, ENSO, and the SPDO are defined, many studies show that the PDO and SPDO are characterized by the Pacific-wide ENSO-like pattern but with stronger extratropical signatures and meridionally broader tropical structures on the interannual time scales relative to ENSO (e.g., Power and Colman 2006; Deser et al. 2010).

The 8-yr Butterworth low-pass-filtered SST indices from both the observations and simulation are shown in Fig. 2. The filtered time series are highly correlated $[r>$ 0.83 ( $>95 \%$ significance) in both the observations and simulation]. Besides, the phase changes of the Pacific Ocean climate indices (Fig. 2) are consistent with the socalled climate regime shift of the late 1970s, which is characterized as the conspicuously rapid transitions between relatively stable atmospheric and oceanic states (O'Kane et al. 2014a).

Correlation analyses have been applied for each pair of the unfiltered monthly SST indices. We found the SST 

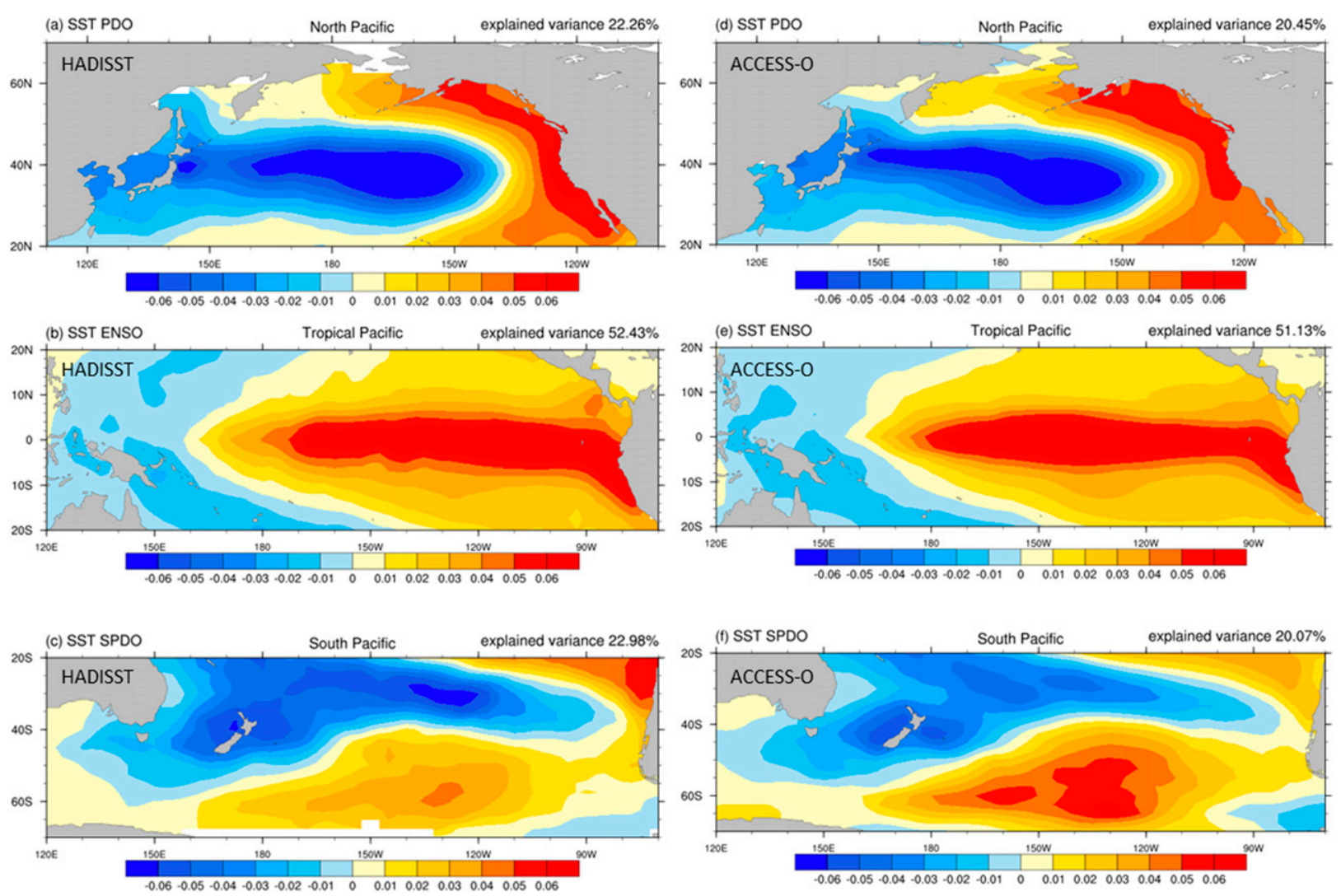

FIG. 1. The leading spatial patterns of the monthly SST for (top) the North Pacific, (middle) the tropical Pacific and (bottom) the South Pacific. (a)-(c) Derived from HadISST during 1948-2007; (d)-(f) derived from ACCESS-O during 1948-2007.

SPDO and ENSO indices (e.g., SST TP-PC1) are more highly correlated relative to the PDO index in both the observations $(r=0.70$ versus 0.46$)$ and simulation $(r=$ 0.62 versus 0.43 ), where all $r$ values are significant at the $95 \%$ level. In this study, the tripole index (TPI; Henley et al. 2015) has been used as a metric (index) for the time variability of the Pacific-wide IPO. It shows the unfiltered TPI is essentially identical to the leading PC of the monthly Pacific basin SSTA (i.e., P-PC1) with correlations of 0.98 in both the observations and simulation.

We have also examined the spectrum for each index (figures are not shown). However, due to the relatively short record lengths and strong autocorrelations (Folland et al. 1999; Liu and Di Lorenzo 2018), the spectra of the PDO and SPDO during 1948-2007 (60 years) in both the HadISST and ACCESS-O are not significant and difficult to identify as spectral peaks. Although less reliable prior to the 1950s (Power et al. 2006), the longer length of the HadISST record may give us a better estimate regarding the spectral analysis, and so on this basis we calculated the SST power spectrum using the complete 147-yr observational HadISST record from 1870 to 2016. The spectrum shows that the PDO has a period of 20-30 years at the $95 \%$ significance level on decadal time scales, and the SPDO has a period of 13-20 years at the $95 \%$ significance level on these same time scales, which is distinct from the time scales of ENSO (up to 6 years). Nevertheless, the PDO exhibits more pronounced decadal signals than the SPDO does in the SST field.

Given the correlation and spectrum analyses above, it is of particular interest to examine the extent to which the slowly varying decadal component contributes to the monthly climate modes. Thus, we calculate the potential predictability for each index. Even though the precise methods on how to derive the decadal component vary in the literature, typically potential decadal predictability has been defined as the ratio of the variance of the slow-varying decadal component with respect to the variance of total variability (e.g., Kirtman et al. 2013).

In this study, we apply the fraction between the variance of 8-yr low-pass-filtered data and the variance of unfiltered monthly data (e.g., Power and Colman 2006) as a measure of potential predictability. A higher potential predictability variance fraction (ppvf) indicates a large proportion of decadal variability with respect to the total and therefore may be more predictable 


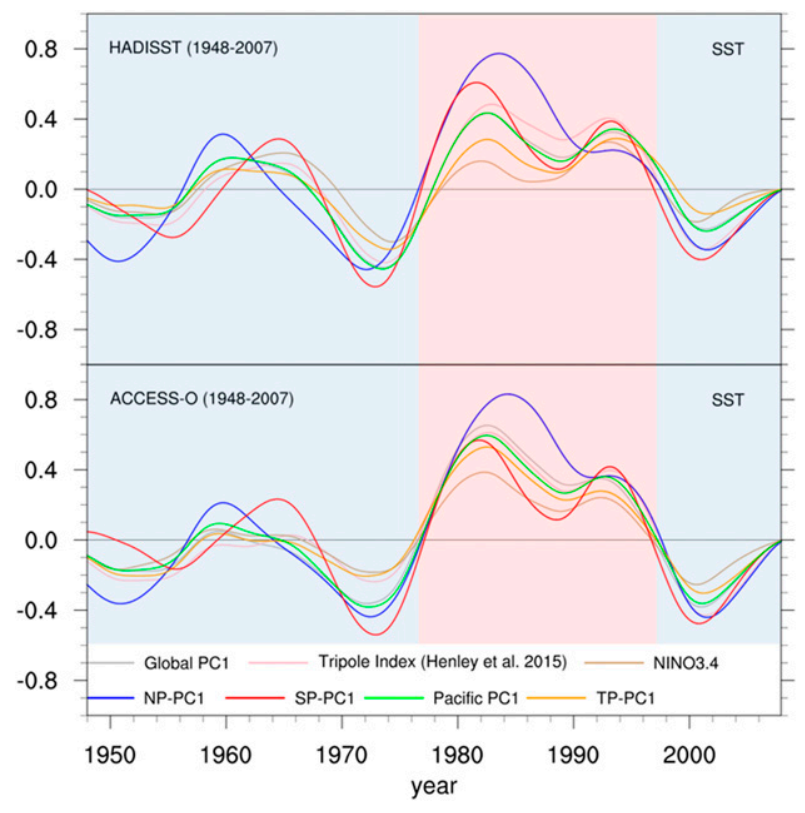

FIG. 2. The 8-yr Butterworth low-pass-filtered tripole index (Henley et al. 2015), Niño-3.4 index, PC1 of near-global SSTA (also known as DEI in Chen and Wallace 2015), PC1 of the North Pacific SSTA (PDO index), PC1 of the South Pacific SSTA (SPDO index), PC1 of the tropical Pacific SSTA (ENSO index), and the PC1 of Pacific basin SSTA derived from (top) HadISST and (bottom) ACCESS-O. All indices are scaled. The positive and negative phases of the IPO shaded in red and blue.

(Kirtman et al. 2013). Although this is a simplified measure of potential predictability and the ppvf is not necessarily indicative of the true decadal predictability (Liu and Di Lorenzo 2018), it nevertheless serves our purpose to understand the differences and similarities of ENSO and the IPO-related variability by giving a uniform standard reference. In fact, the ppvf here shows very similar results with the potential predictability/ predictive skill based on the optimal AR1 models, which will be discussed in section 6 .

The ppvf for each observed and simulated SST index is listed in Table 2. The subtle differences in ppvf values further suggest the atmosphere-forced model performs well in simulating the internal variability. It shows that ENSO (i.e., Niño-3.4 and TP-PC1) has less predictability on the interdecadal time scales (Table 2). However, those indices that encompass the midlatitude regions (i.e., GL-PC1, P-PC1, and TPI) have relatively large predictability ranging between $11 \%$ and $14 \%$ in both the model and observations.

Of all the indices, those regions that only consider the midlatitudes (i.e., NP-PC1 and SP-PC1) have the largest predictability. Especially over the North Pacific, the ppvf of the PDO (NP-PC1) reaches $18.92 \%$ (17.15\%) in the observations (simulation). All the evidence indicates that the surface variability in the midlatitudes can enhance the decadal variability and potential predictability.

\section{Simulated subsurface temperature variability}

\section{a. Vertically averaged temperature}

Power and Colman (2006) and Chung et al. (2017) have previously examined the vertically averaged temperature (VAT), or ocean temperature at a certain depth, and the ratio of variability that occurs on decadal time scales. However, they focused on several hot spots in the South Pacific, for example, the wing index region (Power and Colman 2006) and Tasman Sea (Chung et al. 2017) and suggested that the subsurface dynamics may lead to important sources of decadal predictability.

Using singular spectral analysis applied to observations and CMIP5 model simulations, Monselesan et al. (2015) showed that, on decadal time scales, the maximized sea level variances (where sea level anomaly is a vertically integrated quantity taking account of the integrated effect of the ocean's thermosteric and halosteric properties through the water column) over the Pacific basin arise from the midlatitudes, while the tropical Pacific has less predictability primarily due to the lack of variability on time scales beyond interannual.

While previous studies of IPO predictability have focused mostly on surface climate variability, our study considers the South Pacific-wide SPDO from the surface to the subsurface, and the role of forcing in generating the observed low-frequency variability. The stochastic forcing and generation of SPDO variability has not previously been considered in this way and currently remains unclear.

In the present study, we used VAT from 5- to 280-m depth, encompassing variability within the mixed layer

TABLE 2. The potential predictability variance fraction (\%) of the SST indices and the differences between the observations and simulation (HadISST minus ACCESS-O).

\begin{tabular}{lccccrrr}
\hline \hline & GL-PC1 & Niño-3.4 & TPI & NP-PC1 & TP-PC1 & SP-PC1 & P-PC1 \\
\hline HadISST & 11.64 & 6.47 & 13.69 & 18.92 & 7.94 & 14.76 \\
ACCESS-O & 11.63 & 5.02 & 11.48 & 17.15 & 7.80 & 11.20 \\
Difference & 0.01 & 1.45 & 2.21 & 1.77 & 0.14 & 0.11 & 10.71 \\
\hline
\end{tabular}



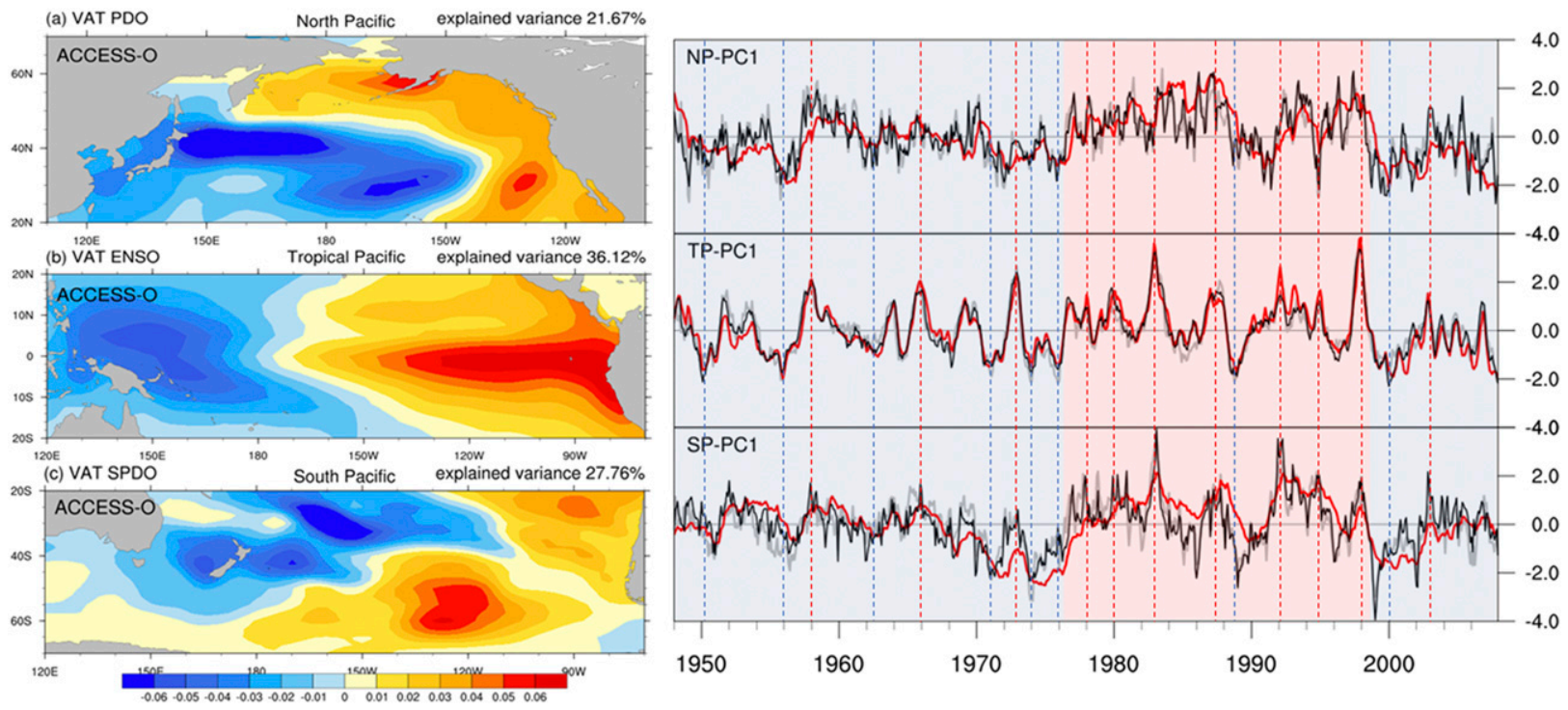

FIG. 3. (left) The leading spatial patterns of the monthly VAT for (a) the North Pacific, (b) the tropical Pacific, and (c) the South Pacific from the ACCESS-O. (right) Comparison of the leading SST PCs (black curve for the ACCESS-O and gray curve for HadISST) and VAT PCs (red curve) for the North Pacific, tropical Pacific, and South Pacific. All the PCs are scaled. The units are arbitrary. Vertical dashed lines indicate the significant El Niño (red) and La Niña (blue) events. Significant El Niño years: 1958, 1966, 1973, 1978, 1980, 1983, 1987, 1988, 1992, 1995, 1997-98, and 2003. Significant La Niña years: 1950-51, 1956, 1962, 1971, 1974, 1976, 1989, and 1999-2000 (available at https://www.esrl.noaa.gov/psd/enso/past_events.html). The positive and negative phases of the slow IPO variability are shaded in red and blue.

and thermocline for most regions. The VAT modes and indices have been constructed using the same regions defined for the SST-based variability. Figure 3 (left) shows the spatial patterns of the simulated VAT variability from each of the three constituent regions of the IPO, explaining $21.67 \%$ (PDO), 36.12\% (ENSO), and $27.76 \%$ (SPDO) of the corresponding total variance. The spatial features of each resemble much of the relative SST counterpart (Fig. 1).

The monthly VAT time series of the PDO, ENSO, and SPDO have also been compared with the SST indices (Fig. 3 right) indicating that due primarily to the direct interaction with the atmosphere, SST has a larger degree of higher-frequency variability. In addition, the SST ENSO and VAT ENSO are highly correlated ( $r=$ 0.94). The high-frequency fluctuations superposed on the slowly varying interdecadal variability are effectively smoothed in the VAT field over the midlatitudes (i.e., VAT NP-PC1 and VAT SP-PC1 in Fig. 3). It is within our expectation that the subsurface dynamics in the midlatitudes can significantly slow down and smooth the local surface variability and further enhance the decadal variability and predictability, which is key for us to understand the source and mechanisms for the PDO and SPDO, and decadal predictability.

The past El Niño and La Niña events are also marked in Fig. 3. We can see the largest amplitude El Niño (La
Niña) events tend to be more frequent during periods when the PDO and SPDO are, respectively, in a positive (negative) phase. Some argue that the PDO and SPDO are partially forced by ENSO (e.g., Newman et al. 2003 and the references therein). It is well recognized that the PDO and SPDO provide ENSO a background state, which can influence the frequency of El Niño and La Niña events over certain decades. In this respect, the predictability of the phases of the PDO and SPDO can give an indication of the relative frequency of occurrence and intensity of ENSO events within a given PDO-SPDO phase or background state.

Although the spatiotemporal features of ENSO and the Pacific decadal modes remain similar for both the surface and subsurface (Figs. 1, 3), we aim here to distinguish the potential predictability of the SPDO from the fast ENSO variability and in contrast to the ENSO-PDO relationship. Table 3 shows the correlations between the simulated VAT indices and the corresponding 8-yr lowpass-filtered SST time series (as shown in Fig. 2). Here, the low-pass-filtered SST time series is used as the reference for comparison with the VAT indices, including the extent to which the unfiltered VAT index is slow and smooth. Of all the indices, the unfiltered VAT SPDO and VAT PDO are the most highly correlated with the corresponding low-pass-filtered SST indices, where $r=0.71$ with the SPDO and $r=0.67$ with the PDO. 
TABLE 3. The correlations between the simulated VAT indices and the corresponding low-pass-filtered SST indices (as shown in Fig. 2) and the potential predictability variance fraction (\%) of the VAT indices. The values in the parentheses are the critical values that are significant at $95 \%$ significance level.

\begin{tabular}{lcccccc}
\hline \hline & GL-PC1 & TPI & NP-PC1 & TP-PC1 & SP-PC1 & P-PC1 \\
\hline$r$ value & $0.54(0.42)$ & $0.51(0.42)$ & $0.67(0.52)$ & $0.40(0.30)$ & $0.71(0.56)$ & $0.50(0.37)$ \\
ppvf $(\%)$ & 24.05 & 22.32 & 40.01 & 12.65 & 47.81 & 19.03 \\
\hline
\end{tabular}

Compared with the ppvf of the SST indices (Table 2), the ppvf of the VAT indices (Table 3 ) is greater, especially for the SPDO (14.65\% versus $47.81 \%$ ) and PDO ( $17.15 \%$ versus $40.01 \%)$. Even though the mechanisms by which these Pacific decadal variations shift phase remains unknown, the VAT SPDO and VAT PDO do give us some cause for optimism that they are potentially useful indicators of when climate regime phase changes may occur.

Figure 4 shows propagating Rossby waves in the VAT across the North Pacific (meridionally averaged over $25^{\circ}-40^{\circ} \mathrm{N}$ ) and South Pacific (meridionally averaged over $25^{\circ}-40^{\circ} \mathrm{S}$ ). Particularly evident is that the Rossby waves seem to be motionless east of $180^{\circ}$ longitude over the South Pacific in the vicinity of the Kermadec Ridge (see the topography in Fig. 4d). VAT in this region clearly exhibits significant decadal signals whose variations are consistent with the IPO phase (Fig. 4c).

Previous studies have explored the source of decadal variability over this region (i.e., the green box in Fig. 4b) as being caused by baroclinic instabilities (Qiu and Chen 2004; O'Kane et al. 2014b). By applying instability theory, O'Kane et al. (2014b) examined the propagation of baroclinic disturbances across the South Pacific (refer to their Figs. 10-14). They found near-stationary patterns eastward of $180^{\circ}$ longitude (refer to Figs. 10 and 11 in O'Kane et al. 2014b), with the amplitude of the baroclinic disturbances increasing west of about $150^{\circ} \mathrm{W}$ (see Fig. 13 in O'Kane et al. 2014b). Their results are consistent with those found here in Fig. 4. By comparing the propagation of planetary Rossby waves and unstable baroclinic disturbances, O'Kane et al. (2014b) showed that the latter better match the complexity apparent in observed altimetric signals in the Pacific than the former, primarily due to their multiscale nature, which are characterized by three distinct phase speeds-one at planetary Rossby wave speeds, one significantly slower corresponding to propagating unstable baroclinic disturbances, and one that is trapped by topography (their Fig. 14).

In the present study, we show that the near-stationary patterns occurring in the western subtropical South Pacific (the green box in Fig. 4b) correspond to an enhancement of the signal of interdecadal variability over the western subtropical South Pacific. The subsurface processes driving the standing wave patterns in the subtropical southwest Pacific described by O'Kane et al. (2014b) are now clarified via analysis of the propagation of the VAT and directly linked to the phase changes of the large-scale climate variability IPO. The significant persisting unfiltered decadal signals identified in our research provide a potential focus for understanding the predictability of interdecadal variability.

\section{b. Vertical temperature structure}

To explore spatial and temporal features of ENSO and IPO-related variability in the vertical, we also examined the vertical structure of the simulated ocean temperature (which we call OT; from the surface to 600-m depth) latitude by latitude. [Note that this contrasts with the VAT presentation (averaged in the vertical), which provides horizontal map snapshots of the vertically averaged temperatures.] For this purpose, the EOF analysis is performed for each latitude across the Pacific. For convenience, we display only meridional averages over the North Pacific $\left(25^{\circ}-50^{\circ} \mathrm{N}\right)$, tropical Pacific $\left(20^{\circ} \mathrm{S}-20^{\circ} \mathrm{N}\right)$, and South Pacific $\left(25^{\circ}-50^{\circ} \mathrm{S}\right)$, respectively. Figure 5 shows the leading vertical EOF patterns for the North, tropical, and South Pacific, which explain $26.55 \%, 56.74 \%$, and $22.10 \%$ of the corresponding variance, respectively.

The vertical OT pattern over the tropical Pacific (Fig. 5b) is strongest along the slope of the thermocline, with deeper negative anomalies on the western side of the basin and shallower positive anomalies on the eastern side. The OT PC1 for the tropical Pacific is highly correlated with the SST ENSO and VAT ENSO (Fig. 5e). The similar temporal variability in SST, VAT, and OT indicates that annual/interannual ENSO variability dominates both the surface and subsurface Pacific over the tropical regions.

The vertical pattern over the South Pacific (Fig. 5c) coincides well with the bottom topography (Fig. 4d). Largest loadings are seen eastward of the Kermadec Ridge (roughly along $180^{\circ}$ ), which are well explained by the stationary Rossby wave pattern. The energy seems to be blocked and amplified along the east edge of the Kermadec Ridge (e.g., Fig. 2 in Maharaj et al. 2005) and extends to a depth of around $400 \mathrm{~m}$. This signal is substantially different to the corresponding region in the North Pacific (Fig. 5a), where the largest loadings are 
(a) North Pacific $(25 \mathrm{~N}-50 \mathrm{~N})$

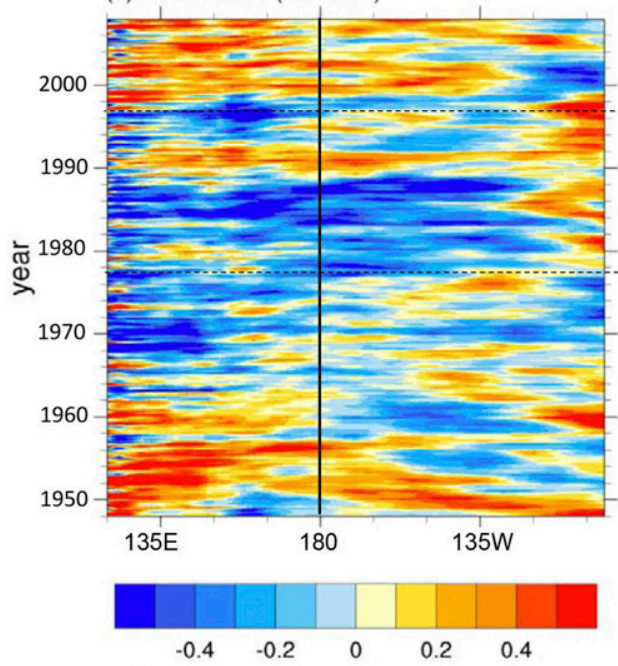

(b) South Pacific (25S-50S)

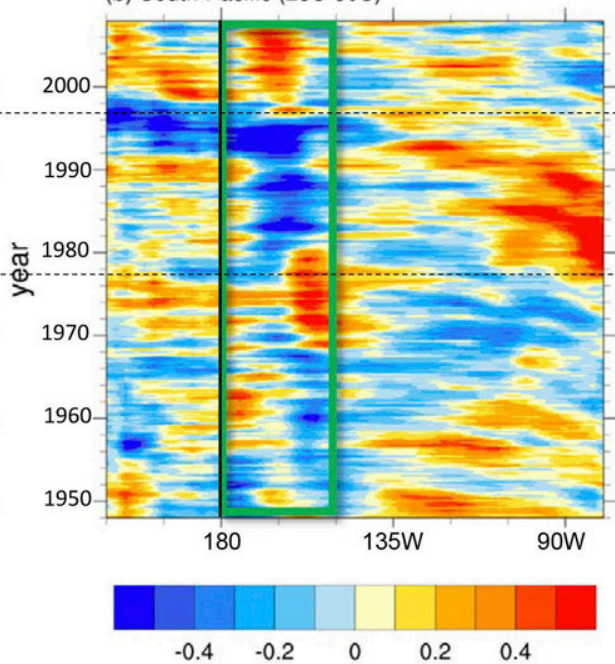

(C)

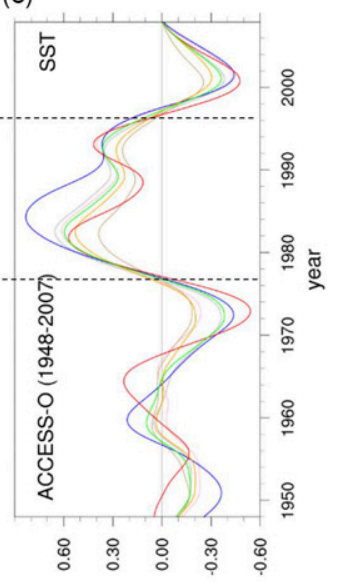

(d)

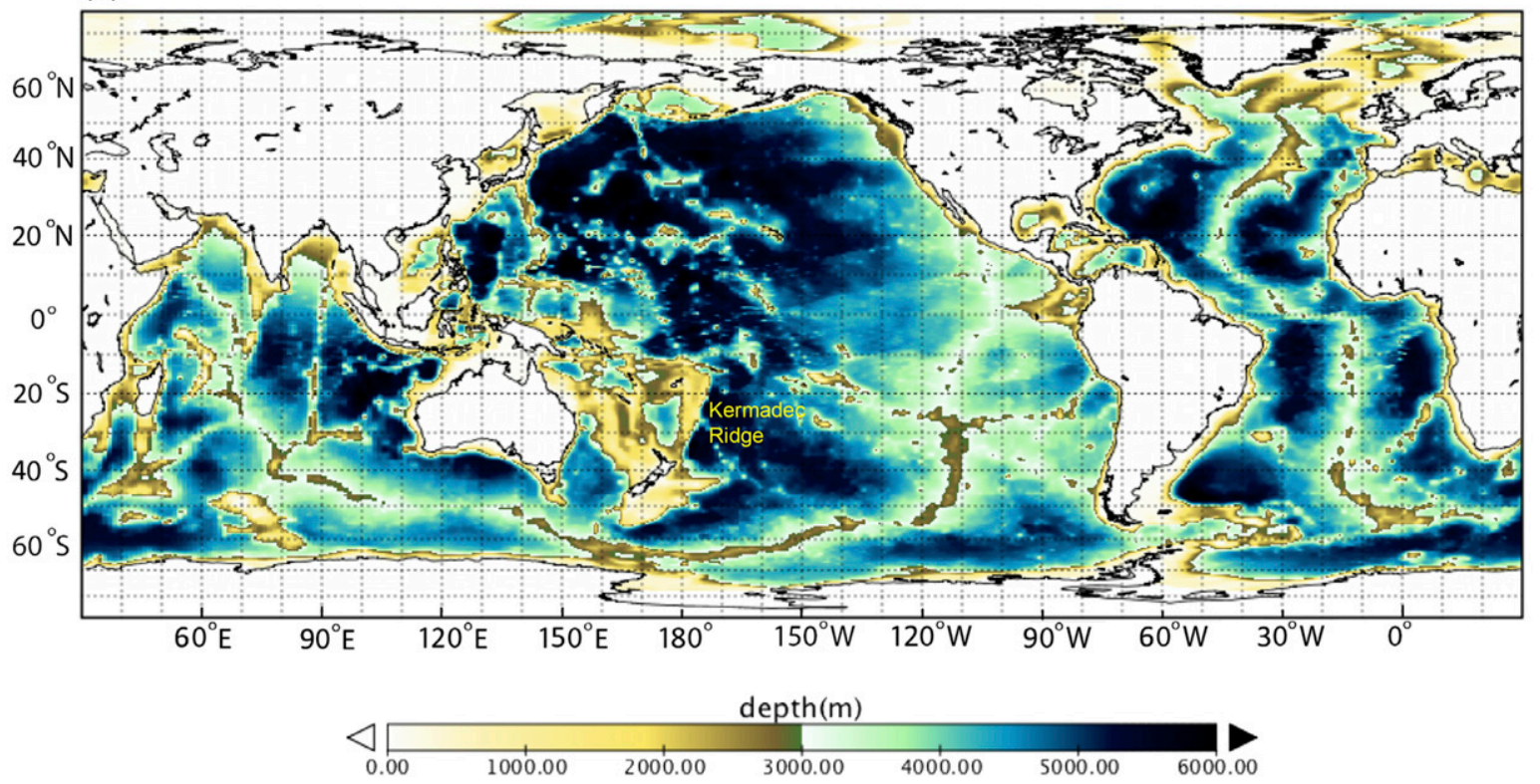

FIG. 4. Hovmöller plot (time vs longitude) showing the propagation of monthly vertically averaged temperature (top $280 \mathrm{~m}$ ) averaged over (a) the North Pacific $\left(25^{\circ}-40^{\circ} \mathrm{N}\right)$ and (b) South Pacific $\left(25^{\circ}-40^{\circ} \mathrm{S}\right)$. The $180^{\circ}$ longitude is marked as the reference longitude. The green box shows the region that exhibits prominent decadal variability. (c) The simulated 8-yr Butterworth low-pass-filtered SST indices (as shown in Fig. 2). The horizontal dotted lines represent the two most recent IPO phase transitions. (d) The model topography (m). The Kermadec Ridge $\left(20^{\circ}-40^{\circ} \mathrm{S}, 180^{\circ}\right)$ has been labeled on the map.

concentrated in the shallower ocean (down to around 200-m depth). Meanwhile, the OT-PCs over the North Pacific and South Pacific (Figs. 5d,f) correlate strongly with the corresponding VAT indices and remain significant interdecadal features.

\section{Sectoral correlation analysis}

From the earlier discussion, we might expect the IPOrelated variability and predictability to primarily arise from subsurface dynamics in the midlatitudes in both hemispheres. Ocean dynamics are the major processes that maintain and enhance the interdecadal variability and predictability. Motivated by exploring the observed interdecadal variability and understanding the mechanisms by which this variability arises, a number of hot spots and climate indices have been introduced, for example, the wing index (Power and Colman 2006), the Kuroshio Extension index (KOE; Qiu 2003; Frankignoul et al. 2011), the spiciness index over the 

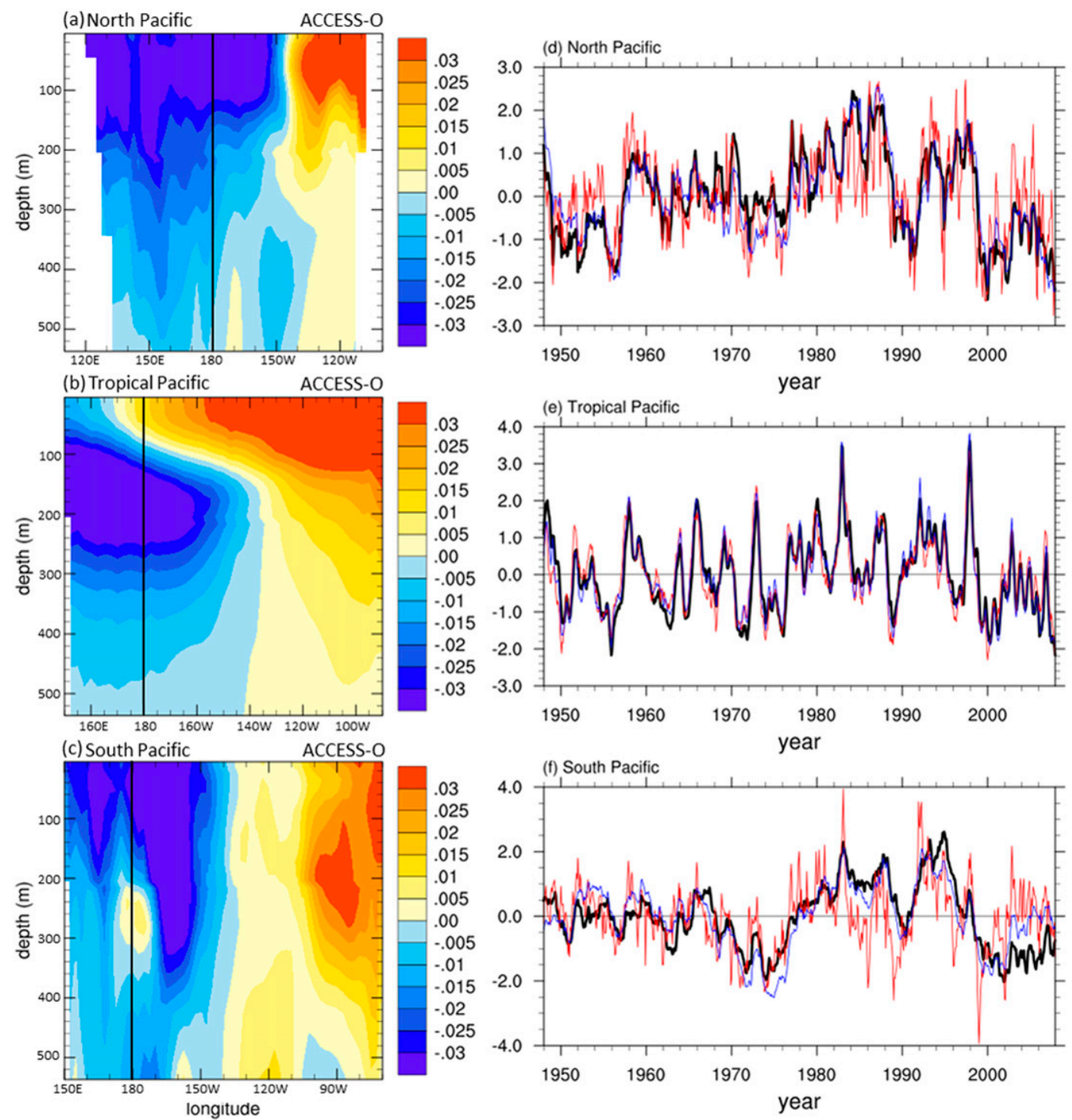

FIG. 5. Longitude-depth section of EOF1 of meridionally averaged ocean temperatures over the (a) North Pacific $\left(25^{\circ}-50^{\circ} \mathrm{N}\right),\left(\right.$ b) tropical Pacific $\left(20^{\circ} \mathrm{S}-20^{\circ} \mathrm{N}\right)$, and (c) South Pacific $\left(25^{\circ}-50^{\circ} \mathrm{S}\right)$. They explain $26.55 \%, 56.74 \%$, and $22.10 \%$ of the variance, respectively. The $180^{\circ}$ longitude is marked as the reference longitude. (d)-(f) The corresponding PC1 (black curves) of the ocean temperatures. For comparison, the leading SST PCs (red curve) and VAT PCs (blue curve) for the North Pacific, tropical Pacific, and South Pacific are also shown in (d)-(f).

subtropical South Pacific (O'Kane et al. 2014a), the TPI (Henley et al. 2015; 2017), and the regions 2, 6, and 7 identified in the study by Chung et al. (2017).

To comprehensively characterize interdecadal variability in the Pacific, we define here a scaled box of dimensions $30^{\circ}$ in longitude and $10^{\circ}$ in latitude, which is sequentially shifted every $5^{\circ}$ in latitude and $30^{\circ}$ in longitude over $45^{\circ} \mathrm{S}-45^{\circ} \mathrm{N}, 150^{\circ} \mathrm{E}-90^{\circ} \mathrm{W}$. Then, we area average each box to construct the area-averaged SST and VAT index (time series). As shown in Fig. 6, we calculate the correlations between each box index and the NP-PC1, TP-PC1, and SP-PC1 for SST and VAT, respectively. The values have been labeled in the corresponding regions and different colors represent different variability-dominated regions (Fig. 6).

In SST (Fig. 6a), the PDO signal dominates the North Pacific, including the KOE region, central and northeast Pacific regions, which coincide well with other PDO-related indices [e.g., KOE index (cf. Fig. 1 in Frankignoul et al. 2011), and TPI (Henley et al. 2015; region 1 in their Fig. 1)]. Interestingly, we can also see the near-symmetric patterns over the midlatitude South Pacific (blue colored in Fig. 6a) similar to the North Pacific (green colored in Fig. 6a). It shows that the Tasman Sea and central South Pacific (east 

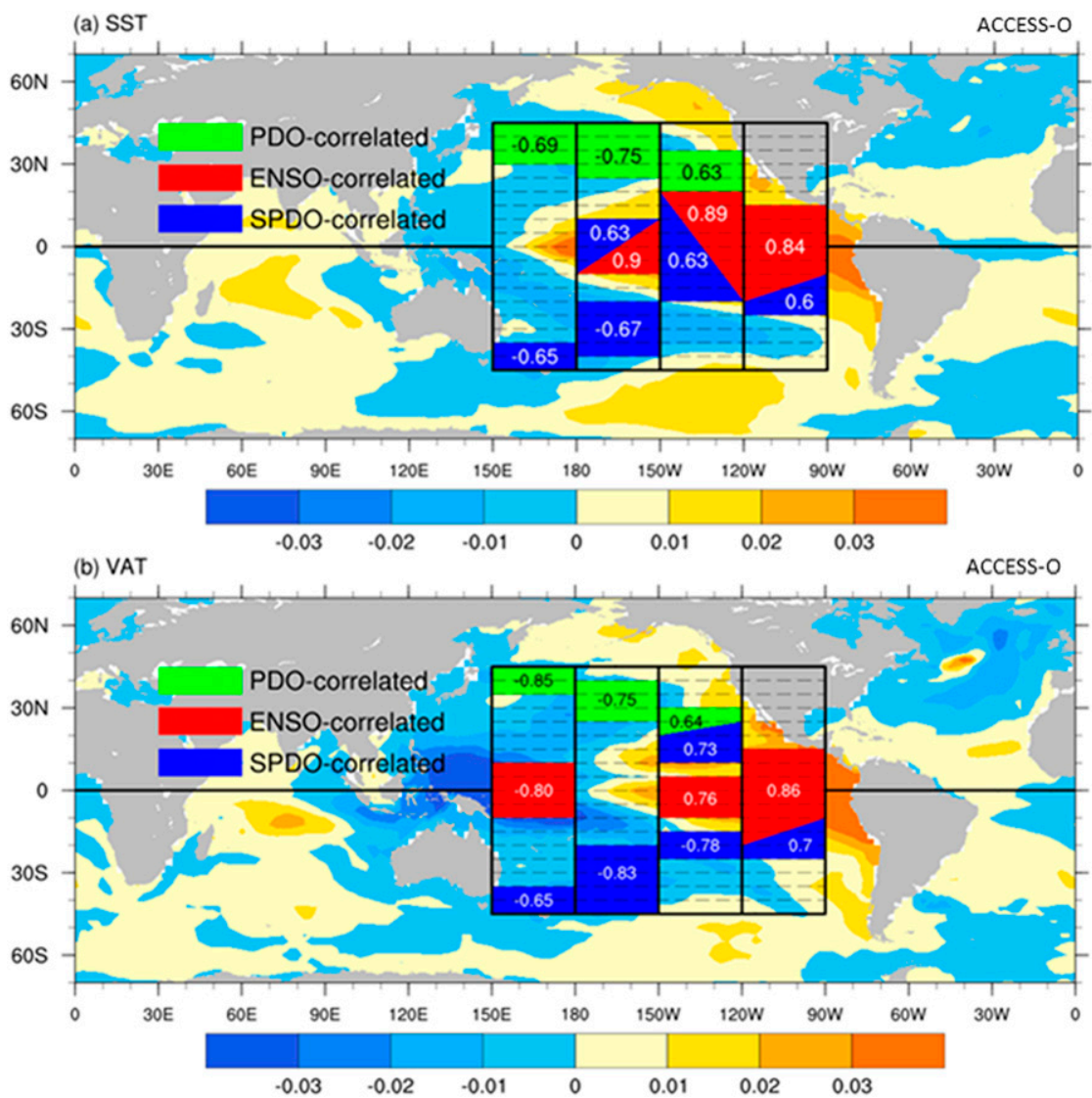

FIG. 6. Correlation maps between the area-averaged box (each has dimensions $30^{\circ}$ in longitude and $10^{\circ}$ in latitude) index and PC time series of the PDO, ENSO, and SPDO for (a) SST and (b) VAT. Correlation values have been labeled in the corresponding regions and different colors represent different variability-dominated regions (green is for the PDO, red is for ENSO, and blue is for the SPDO). Significance tests take account of serial correlation according to Davis (1976). The VAT SPDO has the highest critical value of correlation $\left(\left|r_{c}\right|=\right.$ 0.6 at the $95 \%$ significance level) due to the strong persistence. For the convenience of display, the correlations whose absolute values are larger than $\left|r_{c}\right|=0.6$ are shown. The different colored triangles and trapezoids indicate the regions are overlapped by two indices. For example, the red and blue trapezoids in the rightmost column indicate ENSO and the SPDO overlap between $10^{\circ}$ and $20^{\circ} \mathrm{S}$. The background patterns are the leading EOF for SST in (a) and VAT in (b), which explain $15.94 \%$ and $17.04 \%$, respectively, of the corresponding variances.

of the Kermadec Ridge) exhibit strong SPDO signatures, which are consistent with Chung et al. (2017; their region 6 for the Tasman Sea) and Henley et al. (2015; their region 3 for the South Pacific). Besides, the surface SPDO signals are broadly overlapped with the ENSO variability in the tropical region, indicating the SST SPDO is more strongly coupled with ENSO relative to the SST PDO.

Compared with the SST correlation map (Fig. 6a), similar patterns can also be found in VAT over the midlatitudes (Fig. 6b). However, we can see that the VAT SPDO (blue colored in Fig. 6b) is decoupled with the tropical variability (red colored in Fig. 6b) and confines its signature to the midlatitudes, indicating that a prominent reddening process takes place in the upper South Pacific. It is evident that the trapped mode documented by O'Kane et al. (2014b) at the Kermadec Ridge gives rise to, or enhances, the interdecadal signal over the region eastward of $180^{\circ}$ longitude. The VAT PDO (green colored in Fig. 6b) resembles its SST counterpart and dominates the midlatitude North Pacific, a region characterized by significant interdecadal variability in both the surface and subsurface.

The obvious temporal correlations between the PDO, SPDO, and low-frequency ENSO variability (e.g., Fig. 2) have led to a general understanding that the PDO and SPDO are regarded as "ENSO-like" variations or 
(a) SST ENSO vs. SST PDO

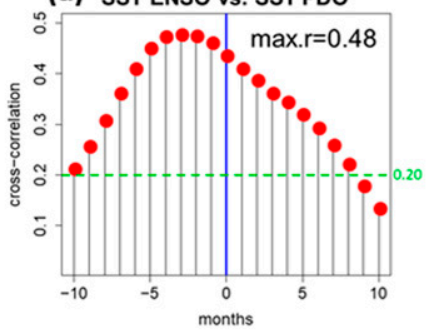

(b) SST ENSO vs. SST SPDO

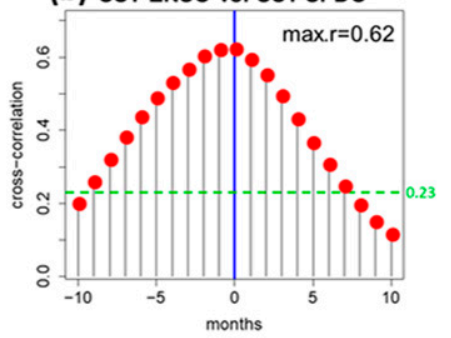

(c) SST SPDO vs. SST PDO

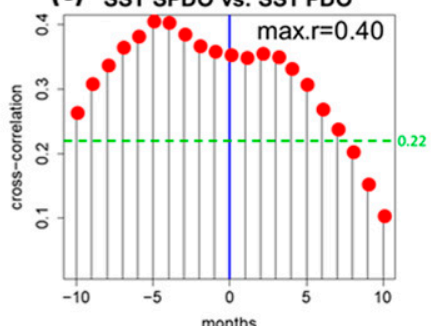

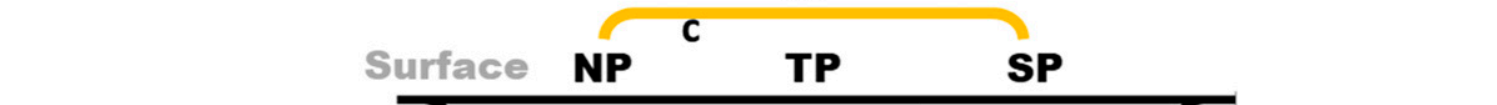

(d) SST PDO vs. VAT PDO
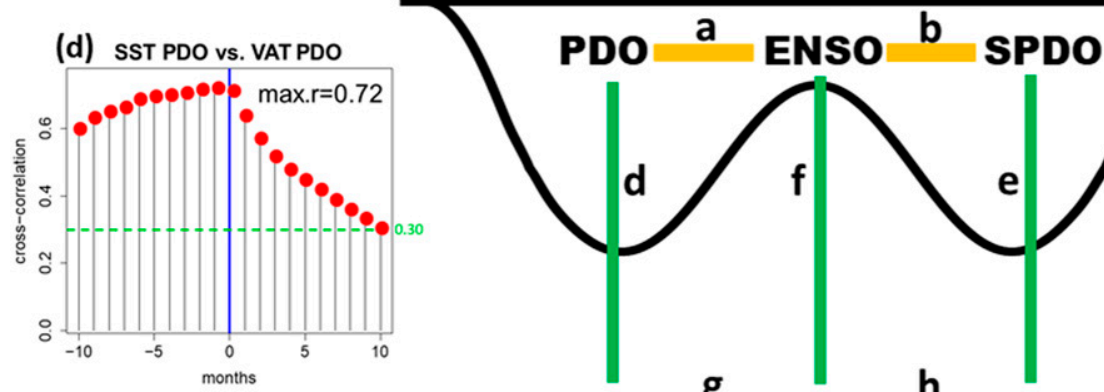

Sulb-surface PDO $g$ ENSO ${ }^{h}$ SPDO

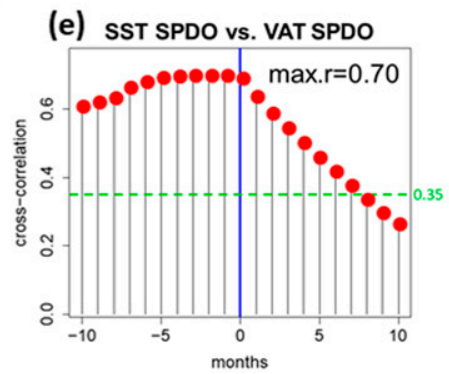

i

(f) SST ENSO vs. VAT ENSO

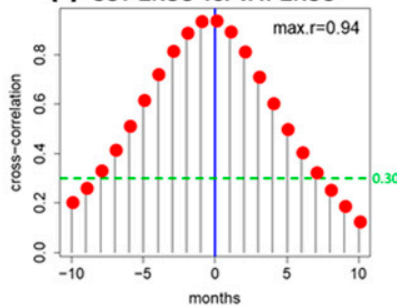

(g) VATENSO vs. VAT PDO

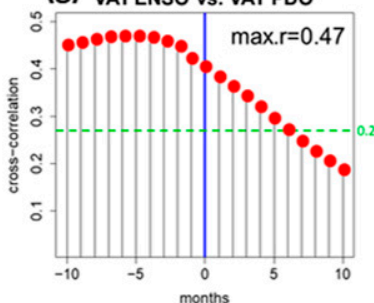

(h) VATENSO vs. VAT SPDO

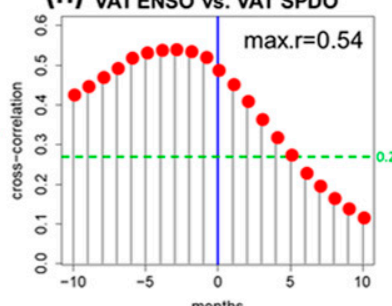

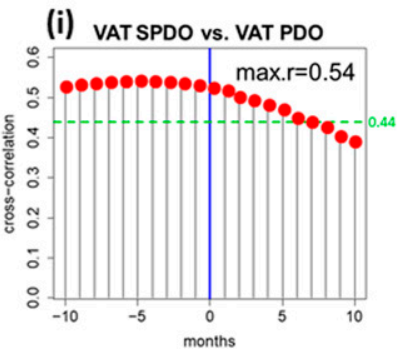

FIG. 7. (a)-(i) Cross correlations between different pairs of surface and subsurface indices of the PDO, ENSO, and SPDO. The green dashed line indicates the critical value at the $95 \%$ significance level, and each critical value has been labeled on the right. The schematic in the middle represents the meridional (zonal mean) cross section of the thermocline (e.g., approximated as the $14^{\circ} \mathrm{C}$ isotherm) as a function of depth and latitude.

more broadly the background state to ENSO. To compare their lead-lag relationships, we calculate cross correlations for different time series pairs of variability (summarized in Fig. 7). Broadly, we can see that the tropical variability leads the midlatitude variability, the surface leads the subsurface, and the South Pacific leads the North Pacific (Fig. 7).

As shown in Fig. 7, the SST SPDO is strongly correlated with ENSO ( $r=0.62$ with 0 lag in Fig. 7b). The SST PDO also exhibits ties with variability in the tropical Pacific, where we see changes in tropical Pacific SSTs leading SSTs over the North Pacific by 3 months $(r=0.48$ in Fig. 7a). Meanwhile, the subsurface PDO and SPDO are highly correlated to their relative surface counterpart ( $r=$ 0.71 and 0.68 , respectively) but with more interdecadal signature (also see in our Fig. 3). The surface variability in the tropical Pacific is dominated by interannual time scales located in the subsurface, which contributes to the high correlation between SST ENSO and VAT ENSO $(r=0.94$ with 0 lag in Fig. 7f). Primarily due to the tighter relationship between ENSO and the SPDO relative to the relationship of ENSO-PDO, we find that the variability over the South Pacific tends to lead variations in the North Pacific ( $r=0.40$ with a 5-month lead at the surface, and $r=0.54$ with a 6 -month lead in the subsurface).

The schematic in Fig. 7 illustrates the meridional cross section of the thermocline (e.g., approximated as the $14^{\circ} \mathrm{C}$ isotherm) with deep thermal layers in the midlatitudes of the Pacific relative to that in the tropical Pacific. The structure of the thermocline across the $\mathrm{Pa}$ cific Ocean is consistent with the distribution of the Pacific decadal variability. 
(a) SST

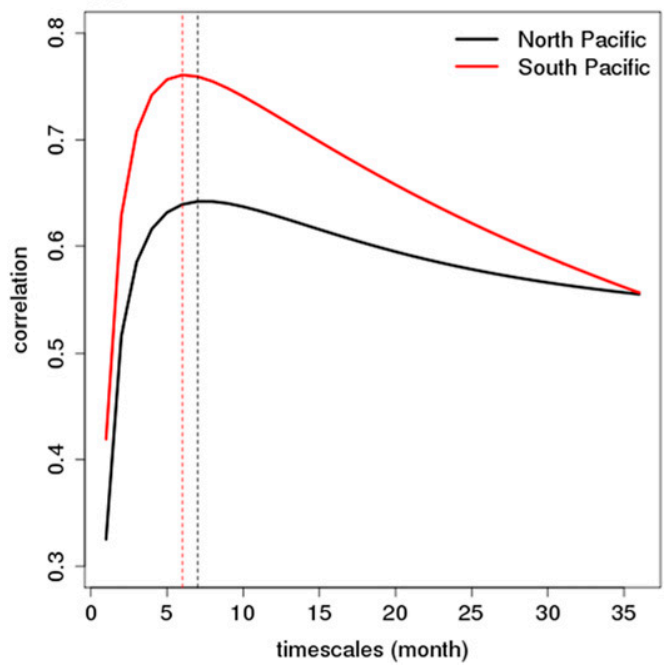

(b) VAT

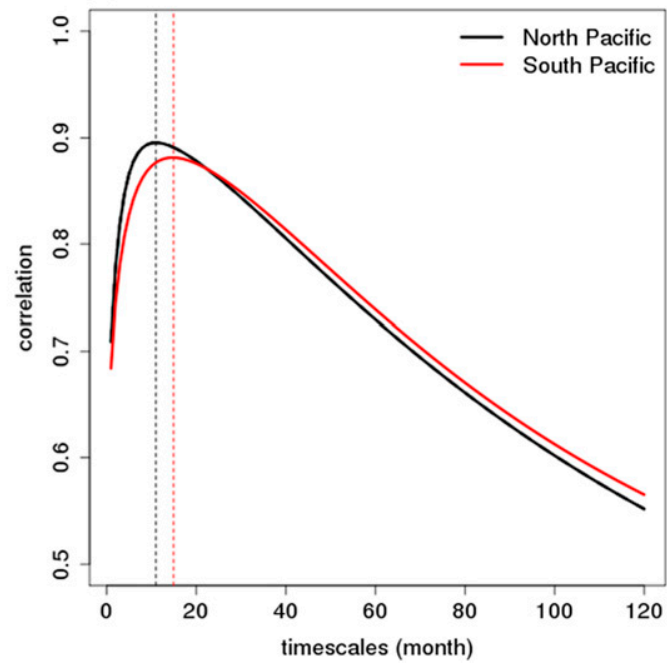

FIG. 8. Correlation skill of integrated PDO (black curve) and SPDO (red curve) for different values of the damping time scales (a) $\tau_{\text {sur }}$ and (b) $\tau_{\text {sub. }}$ Vertical dotted lines indicate the optimal damping time scales.

\section{Stochastically forced PDO and SPDO variability}

Studies on IPO-related decadal climate variability have developed along two major lines [see the review paper by Liu (2012)]. One line assumes the IPO-related variability is self-exciting, while the other adopts the stochastic theory and considers the IPO to be forced by stochastic/atmospheric variability.

We adopt the latter and suppose the ocean is not a self-sustaining system, but rather the atmospheric forcing gives rise to fluctuations in the ocean. Thus, we follow the AR1 null hypothesis approach undertaken in previous studies (Frankignoul and Hasselmann 1977; Newman et al. 2003, 2016; Power and Colman 2006; Di Lorenzo and Ohman 2013), but here applied to oceanic changes separately over the South Pacific and North Pacific, to assess the contributions from each hemisphere. The AR1 model can be written as

$$
\frac{d \Phi(t)}{d t}=f(t)-\frac{\Phi(t-\Delta t)}{\tau_{\text {sur }}}
$$

where $\Phi(t)$ is the surface ocean state and is forced by the atmospheric noise $f(t)$. Here $\tau_{\text {sur }}$ is the surface ocean memory time scale and reflects the damping scale due to surface oceanic processes. The different damping scales $\tau_{\text {sur }}$ have been tested (ranging from 1 to 36 months) in the present AR1 model. The correlation skill of the integrated PDO (SPDO) for different values of the damping scale has been compared in Fig. 8a. According to the correlation skill, the optimal damping time scales for the North Pacific and South Pacific are $\tau_{\text {sur }}=7$ and 6 months, respectively.
By using the Aleutian low (AL) variability (Fig. 9a) and PSA1 variability (Fig. 9c) as the forcing terms in Eq. (1), respectively, we reconstruct the AR1 PDO index and AR1 SPDO index (Figs. 9b,d). The correlation coefficient between the AR1 PDO and ACCESS-O PDO is $r=0.64$.

In the present study, we are particularly interested in understanding the potential relationship between the PSA1 pattern variability and the SPDO (Fig. 9d), which would amount to new understanding of the role of the South Pacific variability in decadal scale changes. Importantly, we find that with the PSA1 forcing, the reconstructed AR1 surface SPDO is indeed highly correlated with the ACCESS-O SPDO $(r=0.76)$, a result that suggests an even tighter relationship between the PSA1 and SPDO than between the AL and PDO.

All the evidence indicates that the North Pacific and South Pacific surface oceans act to redden the atmospheric noise significantly. The AR1-based integration filters the high-frequency component of the atmospheric forcing and produces a signal that is characterized by stronger low-frequency variability.

As discussed earlier, the subsurface variability (e.g., VAT) also acts to low-pass filter the surface variability (here, SST). Following Di Lorenzo and Ohman (2013), we next apply a double-integration AR1 hypothesis to explain the subsurface variability, represented as

$$
\frac{d \Psi(t)}{d t}=\Phi(t)-\frac{\Psi(t-\Delta t)}{\tau_{\text {sub }}},
$$




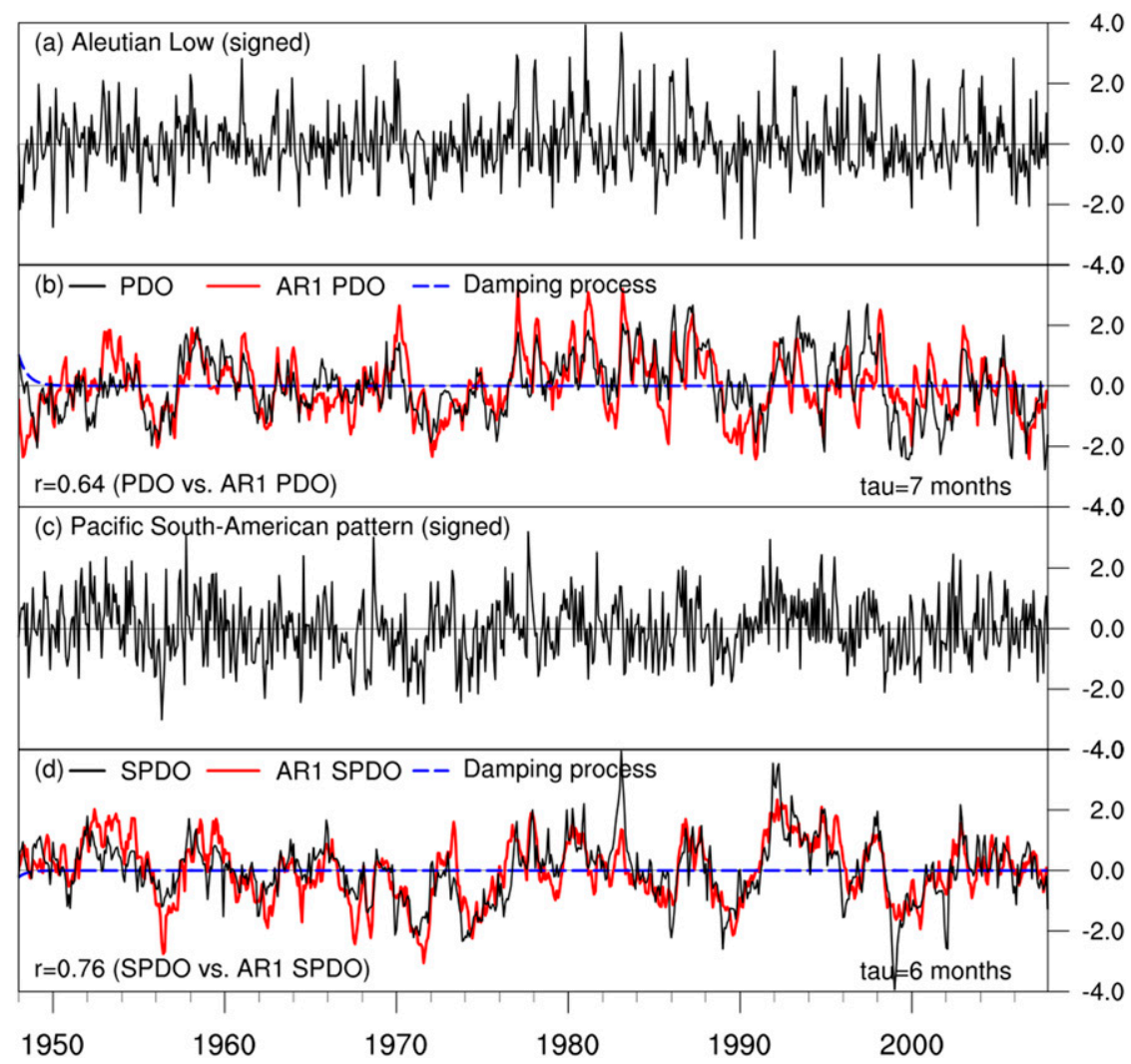

FIG. 9. The AR1 model for the monthly (b) SST PDO index and (d) SST SPDO index. The black curve is for the ACCESS simulation, the red curve is for the AR1 model, and the blue dashed curve indicates the ocean damping process without atmospheric forcing. The (a) atmospheric Aleutian low index and (b) Pacific-South American pattern 1 index. For convenience, all the time series are scaled in the figures.

where $\Psi(t)$ is the subsurface ocean state and is forced by the surface ocean state $\Phi(t)$ in Eq. (1). Here $\tau_{\text {sub }}$ is the subsurface ocean memory time scale. Here, the first integration is from the atmosphere to the surface ocean, while the second integration is from the surface ocean to the subsurface ocean. The different subsurface damping scales $\tau_{\text {sub }}$ have been tested (ranging from 1 to 120 months) in the second integrated AR1 model. The optimal subsurface damping time scales for the North Pacific and South Pacific are $\tau_{\text {sub }}=12$ and 15 months, respectively (Fig. 8b).

Figure 10 shows an example of using Eq. (2) to integrate the PDO and SPDO with optimal damping time scales for the North Pacific and South Pacific, respectively. We can see that when $\tau_{\text {sub }}>\tau_{\text {sur }}$, the double integration of the atmospheric white noise leads to an AR1-based time series with prolonged and smooth low-frequency variations (Fig. 10, red curves), which exhibit much stronger and significant correlations of $r=0.89$ ( $>95 \%$ significance) and 0.88 (>95\% significance) for the VAT PDO and VAT SPDO, respectively (black curves in Fig. 10).
Taking the standard AR1 and double integrated AR1 hypotheses together, our results suggest that the VAT PDO and VAT SPDO can be considered as the reddened response to the corresponding surface variability or cumulative integrated response to the white-noise atmospheric variability.

Figure 11 shows the normalized mean-square prediction errors of the PDO and SPDO from the doubly integrated AR1 models with optimal damping scales of 7 and 6 months for the SST PDO and SST SPDO, and 12 and 15 months for the VAT PDO and VAT SPDO with lead times of up to 48 months. We can see that the predictive skill of the PDO and the SPDO are significantly increased when taking account of the vertically averaged temperatures (subsurface) relative to only the sea surface temperatures. We find that of all the indices, the VAT SPDO has the largest predictability (lead times), and the SST SPDO also has a relatively larger predictability compared with the SST PDO at leads of up to 8 months. Using a typical mean-squared prediction error of 0.5 here as a 


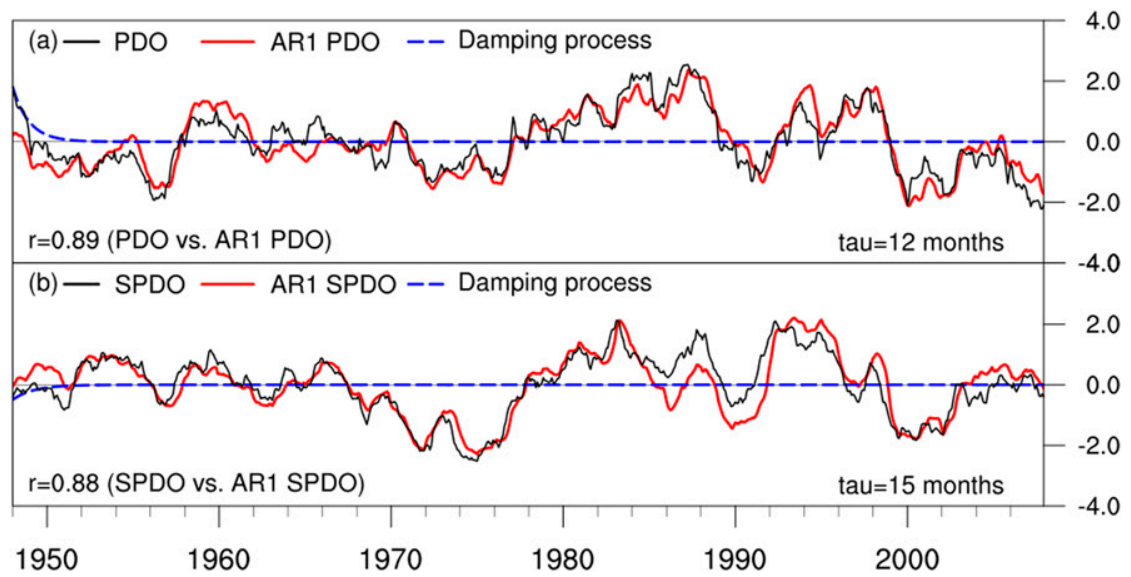

FIG. 10. Double integrated AR1 model for the (a) VAT PDO index, and (b) VAT SPDO index. The black curve is for the ACCESS simulation, the red curve is for the double integrated AR1 model, and the blue dashed curve indicates the ocean damping process without ocean surface variability forcing. All time series are scaled.

reference of useful predictions, we find that the subsurface SPDO (VAT SPDO) exhibits significant skill at lead times of up to 11 months, providing potentially predictive skill up to 2 months in advance of the VAT PDO.

\section{Summary and discussion}

From the perspective of the time scale of SST predictability, atmospheric variability can be considered chaotic and/or stochastic. From weather prediction, we know that the synoptic atmosphere varies rapidly and cannot be predicted beyond 7-10 days (Lorenz 1963), and is thus unpredictable on the much longer dynamical time scales of the ocean (Di Lorenzo and Ohman 2013). It follows that predictability of the ocean- atmosphere climate system on interannual to multidecadal time scales resides primarily in the ocean dynamics. Even though the ocean processes strongly redden the surface variability, especially over the midlatitudes, the surface variability is still influenced directly by stochastic atmosphere noise. Unpredictable high-frequency noise superimposed on the low-frequency variability (Fig. 3) increases the uncertainty and makes it difficult to predict the surface SST variability on interdecadal time scales.

To avoid the influence of unpredictable noise and obtain the slow interdecadal variability, a large number of studies apply low-pass time filtering to their data. Technically, low-pass time filtering can minimize the effects of subscale variability. However, the filtered variability is not necessarily predictable to

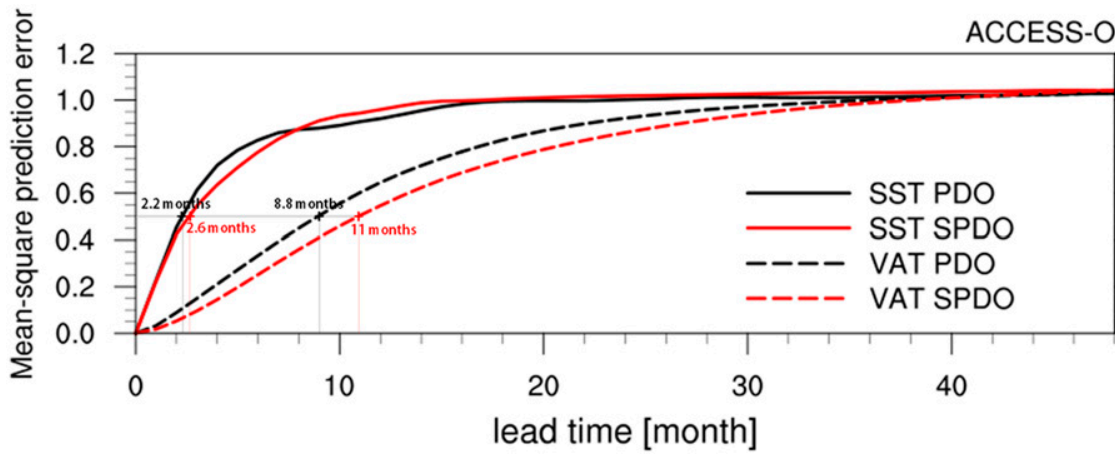

FIG. 11. Mean-square prediction errors from the optimal AR1 models, normalized by the corresponding variances. The horizontal line indicates the reference prediction error of 0.5 . The vertical lines indicate the corresponding lead time. Each lead time under the prediction error of 0.5 has been labeled. 
any extent (see e.g., Power and Colman 2006) and the physical meaning of the filtered variability is reduced relative to the retained variance as a fraction of the total.

For example, we know that ENSO variability is irregular (and can be deemed to be random) on interdecadal time scales. While time filtering of observed ENSO variability reveals interdecadal fluctuations (Fig. 2), care must be taken in interpreting these signals as these fluctuations explain very little of the total tropical Pacific variability (see Fig. 2 in Monselesan et al. 2015).

At the same time, we explored the subsurface variability of the ocean to understand the sources of interdecadal variability and mechanisms. The subsurface variability over the midlatitudes in both hemispheres (i.e., VAT NP-PC1 and VAT SP-PC1 in Fig. 3) can be viewed simplistically as a low-frequency approximation to the corresponding observed SST variability. Nevertheless, the unfiltered subsurface variability arising from internal ocean dynamics and atmospheric forcing provides the dynamic mechanism to significantly maintain and enhance interdecadal variability and predictability in the midlatitudes.

Using an AR1 null hypothesis, we have demonstrated that the time variability of the PSA1 pattern is a critically important atmospheric driver of decadal climate variability in the South Pacific. This was identified in the surface SPDO, in a manner analogous to previous studies of the relationship between the Aleutian low and PDO in the North Pacific-albeit that the relationship in the South Pacific appears to be even stronger. That is, oceanic subsurface processes contribute mainly to the decadal variability over the midlatitudes in both the North Pacific and South Pacific Oceans and act significantly to redden the surface variability, especially over the South Pacific where the surface variability appears to be more tightly coupled to the tropics. We found that the topographically trapped nonlinear baroclinic Rossby wave in the western subtropical South Pacific in the vicinity of the Kermadec Ridge acts to low-pass filter and enhance the decadal signature of the IPO more prominently than anywhere else in the Pacific basin. This suggests that long-term monitoring of climatic variations and their response and sensitivity to changes in anthropogenic forcing may be effectively targeted at a few wellchosen locations such as those described here.

Finally, we show that potential predictability in terms of both the ratio between total and slow variance and in terms of the doubly integrated AR1 models identifies the upper South Pacific Ocean temperature variability as an important source of predictable low-frequency variability at lead times longer than for the PDO. Further, our results make explicit the different atmospheric and oceanic processes that determine potential predictability in each of the North, tropical, and South Pacific Ocean sectors associated with the IPO. The significantly different atmosphere, ocean dynamics (in particular heat and thermocline variability), and geometry (topography and bathymetry) in each of these regions brings into question the utility of viewing the IPO as a distinct climate mode of variability.

Acknowledgments. We thank the four anonymous reviewers whose suggestions led to a substantial improvement of the paper. JL is grateful for a Ph.D. scholarship provided by the ARC Centre of Excellence for Climate System Science (CE110001028), University of Tasmania tuition fee scholarship, and a Quantitative Marine Science top-up scholarship [including support from the Australian Commonwealth Scientific Research Organisation (CSIRO) Postgraduate scheme]. NJH acknowledges funding support from the ARC Centre of Excellence for Climate Extremes (CE17010023). TJO is supported by the CSIRO Decadal Forecasting Project (https://research.csiro.au/dfp) and NJH and TJO acknowledge support from the National Environmental Science Project Earth Systems and Climate Change (NESP ESCC) Hub project 2.3. This research was undertaken with the assistance of resources from the National Computational Infrastructure (NCI), which is supported by the Australian government.

\section{REFERENCES}

Alexander, M. A., L. Matrosova, C. Penland, J. D. Scott, and P. Chang, 2008: Forecasting Pacific SSTs: Linear inverse model predictions of the PDO. J. Climate, 21, 385-402, https:// doi.org/10.1175/2007JCLI1849.1.

Basher, R. E., and X. Zheng, 1998: Mapping rainfall fields and their ENSO variation in data-sparse tropical southwest Pacific Ocean region. Int. J. Climatol., 18, 237-251, https://doi.org/10.1002/(SICI)1097-0088(19980315)18:3<237:: AID-JOC250>3.0.CO;2-G.

Boer, G. J., 2000: A study of atmosphere-ocean predictability on long time scales. Climate Dyn., 16, 469-477, https://doi.org/ $10.1007 / \mathrm{s} 003820050340$.

_ 2004: Long time-scale potential predictability in an ensemble of coupled climate models. Climate Dyn., 23, 29-44, https:// doi.org/10.1007/s00382-004-0419-8.

Branstator, G., H. Teng, G. A. Meehl, M. Kimoto, J. R. Knight, M. Latif, and A. Rosati, 2012: Systematic estimates of initialvalue decadal predictability for six AOGCMs. J. Climate, 25, 1827-1846, https://doi.org/10.1175/JCLI-D-11-00227.1.

Capotondi, A., M. A. Alexander, C. Deser, and A. J. Miller, 2005: Low-frequency pycnocline variability in the northeast Pacific. 
J. Phys. Oceanogr., 35, 1403-1420, https://doi.org/10.1175/ JPO2757.1.

Chen, D., M. A. Cane, A. Kaplan, S. E. Zebiak, and D. Huang, 2004: Predictability of El Niño over the past 148 years. Nature, 428, 733-736, https://doi.org/10.1038/nature02439.

Chen, X., and J. M. Wallace, 2015: ENSO-like variability: 19002013. J. Climate, 28, 9623-9641, https://doi.org/10.1175/JCLID-15-0322.1.

Chung, C. T. Y., S. B. Power, A. Santoso, and G. Wang, 2017: Multiyear variability in the Tasman Sea and impacts on Southern Hemisphere climate in CMIP5 models. J. Climate, 30, 4413-4427, https://doi.org/10.1175/JCLI-D-16-0862.1.

Davis, R. E., 1976: Predictability of sea surface temperature and sea level pressure anomalies over the North Pacific Ocean. J. Phys. Oceanogr., 6, 249-266, https://doi.org/10.1175/15200485(1976)006<0249:POSSTA > 2.0.CO;2.

Delworth, T. L., and Coauthors, 2006: GFDL's CM2 global coupled climate models. Part I: Formulation and simulation characteristics. J. Climate, 19, 643-674, https://doi.org/10.1175/ JCLI3629.1.

Deser, C., M. A. Alexander, and M. S. Timlin, 2003: Understanding the persistence of sea surface temperature anomalies in midlatitudes. J. Climate, 16, 57-72, https://doi.org/10.1175/1520 0442(2003)016<0057:UTPOSS >2.0.CO;2.

$\longrightarrow,-$, S.-P. Xie, and A. S. Phillips, 2010: Sea surface temperature variability: Patterns and mechanisms. Annu. Rev. Mar. Sci., 2, 115-143, https://doi.org/10.1146/annurev-marine120408-151453.

Di Lorenzo, E., and M. D. Ohman, 2013: A double-integration hypothesis to explain ocean ecosystem response to climate forcing. Proc. Natl. Acad. Sci. USA, 110, 2496-2499, https:// doi.org/10.1073/pnas.1218022110.

Folland, C. K., D. E. Parker, A. Colman, and R. Washington, 1999: Large scale modes of ocean surface temperature since the late nineteenth century. Beyond El Niño: Decadal and Interdecadal Climate Variability, A. Navarra, Eds., SpringerVerlag, 73-102.

_ J. A. Renwick, M. J. Salinger, and A. B. Mullan, 2002: Relative influences of the Interdecadal Pacific Oscillation and ENSO on the South Pacific Convergence Zone. Geophys. Res. Lett., 29, 1643, https://doi.org/10.1029/ 2001 GL014201.

Frankignoul, C., and K. Hasselmann, 1977: Stochastic climate models, Part II Application to sea-surface temperature anomalies and thermocline variability. Tellus, 29, 289-305, https://doi.org/10.3402/tellusa.v29i4.11362.

—, N. Sennéchael, Y.-O. Kwon, and M. A. Alexander, 2011: Influence of the meridional shifts of the Kuroshio and the Oyashio Extensions on the atmospheric circulation. $J$. Climate, 24, 762-777, https://doi.org/10.1175/2010JCLI3731.1.

Frederiksen, C. S., X. Zheng, and S. Grainger, 2016: Simulated modes of inter-decadal predictability in sea surface temperature. Climate Dyn., 46, 2231-2245, https://doi.org/10.1007/ s00382-015-2699-6.

Griffies, S. M., and K. Bryan, 1997: A predictability study of simulated North Atlantic multidecadal variability. Climate Dyn., 13, 459-487, https://doi.org/10.1007/s003820050177.

- and Coauthors, 2009: Coordinated Ocean-ice Reference Experiments (COREs). Ocean Modell., 26, 1-46, https:// doi.org/10.1016/j.ocemod.2008.08.007.

Hasselmann, K., 1976: Stochastic climate models Part I. Theory. Tellus, 28, 473-485, https://doi.org/10.3402/tellusa.v28i6. 11316 .
Henley, B. J., J. Gergis, D. J. Karoly, S. Power, J. Kennedy, and C. K. Folland, 2015: A tripole index for the Interdecadal Pacific Oscillation. Climate Dyn., 45, 3077-3090, https://doi.org/ 10.1007/s00382-015-2525-1.

_ climate model simulations of the Interdecadal Pacific Oscillation. Environ. Res. Lett., 12, 044011, https://doi.org/10.1088/ 1748-9326/aa5cc8.

Hill, K. L., S. R. Rintoul, K. R. Ridgway, and P. R. Oke, 2011: Decadal changes in the South Pacific western boundary current system revealed in observations and ocean state estimates. J. Geophys. Res., 116, C01009, https://doi.org/10.1029/ 2009JC005926.

Holbrook, N. J., and N. L. Bindoff, 1997: Interannual and decadal temperature variability in the southwest Pacific Ocean between 1955 and 1988. J. Climate, 10, 1035-1049, https:// doi.org/10.1175/1520-0442(1997)010<1035:IADTVI >2.0.CO;2. , I. D. Goodwin, S. McGregor, E. Molina, and S. B. Power, 2011: ENSO to multi-decadal time scale changes in East Australian Current transports and Fort Denison sea level: Oceanic Rossby waves as the connecting mechanism. Deep-Sea Res. II, 58, 547-558, https://doi.org/10.1016/ j.dsr2.2010.06.007.

— , and Coauthors, 2014: Decadal climate variability and crossscale interactions: ICCL 2013 expert assessment workshop. Bull. Amer. Meteor. Soc., 95, ES155-ES158, https://doi.org/ 10.1175/BAMS-D-13-00201.1.

Kiladis, G. N., and K. C. Mo, 1998: Interannual and intraseasonal variability in the Southern Hemisphere. Meteorology of the Southern Hemisphere, D. J. Karoly and D. G. Vincent, Eds., Amer. Meteor. Soc., 307-336.

Kirtman, B., and Coauthors, 2013: Near-term climate change: Projections and predictability. Climate Change 2013: The Physical Science Basis, T. F. Stocker et al., Eds., Cambridge University Press, 953-1028.

Lau, K. M., P. J. Sheu, and I. S. Kang, 1994: Multiscale lowfrequency circulation modes in the global atmosphere. J. Atmos. Sci., 51, 1169-1193, https://doi.org/10.1175/15200469(1994)051<1169:MLFCMI>2.0.CO;2.

Leathers, D. J., B. Yarnal, and M. A. Palecki, 1991: The Pacific/ North American teleconnection pattern and United States climate. Part I: Regional temperature and precipitation associations. J. Climate, 4, 517-528, https://doi.org/10.1175/15200442(1991)004<0517:TPATPA > 2.0.CO;2.

Li, S., L. Zhang, and L. Wu, 2017: Decadal potential predictability of upper ocean heat content over the twentieth century. Climate Dyn., 49, 3293-3307, https://doi.org/10.1007/s00382016-3513-9.

Linsley, B. K., G. M. Wellington, and D. P. Schrag, 2000: Decadal sea surface temperature variability in the subtropical South Pacific from 1726 to 1997 A.D. Science, 290, 1145, https:// doi.org/10.1126/science.290.5494.1145.

Liu, Z., 2012: Dynamics of interdecadal climate variability: A historical perspective. J. Climate, 25, 1963-1995, https://doi.org/ 10.1175/2011JCLI3980.1.

-, and E. Di Lorenzo, 2018: Mechanisms and predictability of Pacific decadal variability. Curr. Climate Change Rep., 4, 128144, https://doi.org/10.1007/s40641-018-0090-5.

Lorenz, E. N., 1963: Deterministic nonperiodic flow. J. Atmos. Sci., 20, 130-141, https://doi.org/10.1175/1520-0469(1963) $020<0130: \mathrm{DNF}>2.0 . \mathrm{CO} ; 2$.

Lou, J., X. Zheng, C. S. Frederiksen, H. Liu, S. Grainger, and K. Ying, 2017: Simulated decadal modes of the NH 
atmospheric circulation arising from intra-decadal variability, external forcing and slow-decadal climate processes. Climate Dyn., 48, 2635-2652, https://doi.org/10.1007/s00382016-3229-x.

Lyu, K., X. Zhang, J. A. Church, J. Hu, and J.-Y. Yu, 2017: Distinguishing the quasi-decadal and multidecadal sea level and climate variations in the Pacific: Implications for the ENSOlike low-frequency variability. J. Climate, 30, 5097-5117, https://doi.org/10.1175/JCLI-D-17-0004.1.

Maharaj, A. M., P. Cipollini, and N. J. Holbrook, 2005: Observed variability of the South Pacific westward sea level anomaly signal in the presence of bottom topography. Geophys. Res. Lett., 32, L04611, https://doi.org/10.1029/ 2004 GL020966.

Mantua, N. J., S. R. Hare, Y. Zhang, J. M. Wallace, and R. C. Francis, 1997: A Pacific interdecadal climate oscillation with impacts on salmon production. Bull. Amer. Meteor. Soc., 78, 1069-1079, https://doi.org/10.1175/1520-0477(1997)078<1069: APICOW $>2.0 . \mathrm{CO} ; 2$.

McGregor, S., N. J. Holbrook, and S. B. Power, 2007: Interdecadal sea surface temperature variability in the equatorial Pacific Ocean. Part I: The role of off-equatorial wind stresses and oceanic Rossby waves. J. Climate, 20, 2643-2658, https:// doi.org/10.1175/JCLI4145.1.

Meehl, G. A., and H. Teng, 2012: Case studies for initialized decadal hindcasts and predictions for the Pacific region. Geophys. Res. Lett., 39, L22705, https://doi.org/10.1029/ 2012GL053423.

— , and Coauthors, 2009: Decadal prediction: Can it be skillful? Bull. Amer. Meteor. Soc., 90, 1467-1485, https://doi.org/ 10.1175/2009BAMS2778.1.

- A. Hu, and C. Tebaldi, 2010: Decadal prediction in the Pacific region. J. Climate, 23, 2959-2973, https://doi.org/10.1175/ 2010JCLI3296.1.

— - and Coauthors, 2014: Decadal climate prediction: An update from the trenches. Bull. Amer. Meteor. Soc., 95, 243-267, https://doi.org/10.1175/BAMS-D-12-00241.1.

Mo, K. C., 2000: Relationships between low-frequency variability in the Southern Hemisphere and sea surface temperature anomalies. J. Climate, 13, 3599-3610, https://doi.org/10.1175/ 1520-0442(2000)013<3599:RBLFVI>2.0.CO;2.

Monselesan, D. P., T. J. O'Kane, J. S. Risbey, and J. Church, 2015: Internal climate memory in observations and models. Geophys. Res. Lett., 42, 1232-1242, https://doi.org/10.1002/ 2014 GL062765.

Nadiga, B. T., and T. J. O'Kane, 2017: Low-frequency regime transitions and predictability of regimes in a barotropic model. Nonlinear and Stochastic Climate Dynamics, C. L. E. Franzke and T. J. O'Kane, Eds., Cambridge University Press, 136-158.

Newman, M., 2007: Interannual to decadal predictability of tropical and North Pacific sea surface temperatures. J. Climate, 20, 2333-2356, https://doi.org/10.1175/JCLI4165.1.

—, G. P. Compo, and M. A. Alexander, 2003: ENSO-forced variability of the Pacific decadal oscillation. J. Climate, 16, 3853-3857, https://doi.org/10.1175/1520-0442(2003)016<3853: EVOTPD $>2.0 . \mathrm{CO} ; 2$.

,-- , and J. D. Scott, 2011: An empirical model of tropical ocean dynamics. Climate Dyn., 37, 1823, https://doi.org/ 10.1007/s00382-011-1034-0.

, and Coauthors, 2016: The Pacific decadal oscillation, revisited. J. Climate, 29, 4399-4427, https://doi.org/10.1175/ JCLI-D-15-0508.1.
O'Kane, T. J., R. J. Matear, M. A. Chamberlain, and P. R. Oke, 2014a: ENSO regimes and the late 1970's climate shift: The role of synoptic weather and South Pacific ocean spiciness. J. Comput. Phys., 271, 19-38, https://doi.org/10.1016/ j.jcp.2013.10.058.

,,--- E. C. J. Oliver, and N. J. Holbrook, 2014b: Storm tracks in the Southern Hemisphere subtropical oceans. J. Geophys. Res. Oceans, 119, 6078-6100, https://doi.org/ 10.1002/2014JC009990.

— D. P. Monselesan, and J. S. Risbey, 2017: A multiscale reexamination of the Pacific-South American pattern. Mon. Wea. Rev., 145, 379-402, https://doi.org/10.1175/MWR-D-160291.1.

Power, S., and R. Colman, 2006: Multi-year predictability in a coupled general circulation model. Climate Dyn., 26, 247-272, https://doi.org/10.1007/s00382-005-0055-y.

—, T. Casey, C. Folland, A. Colman, and V. Mehta, 1999: Inter-decadal modulation of the impact of ENSO on Australia. Climate Dyn., 15, 319-324, https://doi.org/10.1007/ s003820050284.

_- M. Haylock, R. Colman, and X. Wang, 2006: The predictability of interdecadal changes in ENSO activity and ENSO teleconnections. J. Climate, 19, 4755-4771, https:// doi.org/10.1175/JCLI3868.1.

_ - and Coauthors, 2017: Towards the prediction of multi-year to decadal climate variability in the Southern Hemisphere. Past Global Changes Mag., 25, 32-40, https://doi.org/10.22498/ pages.25.1.32.

Qiu, B., 2003: Kuroshio Extension variability and forcing of the Pacific decadal oscillations: Responses and potential feedback. J. Phys. Oceanogr., 33, 2465-2482, https://doi.org/ 10.1175/2459.1.

— and S. Chen, 2004: Seasonal modulations in the eddy field of the South Pacific Ocean. J. Phys. Oceanogr., 34, 15151527, https://doi.org/10.1175/1520-0485(2004)034<1515: SMITEF $>2.0 . \mathrm{CO} ; 2$.

Rayner, N. A., D. E. Parker, E. B. Horton, C. K. Folland, L. V. Alexander, D. P. Rowell, E. C. Kent, and A. Kaplan, 2003: Global analyses of sea surface temperature, sea ice, and night marine air temperature since the late nineteenth century. J. Geophys. Res., 108, 4407, https://doi.org/10.1029/ 2002JD002670.

Reason, C. J. C., 2000: Multidecadal climate variability in the subtropics/mid-latitudes of the Southern Hemisphere oceans. Tellus, 52A, 203-223, https://doi.org/10.3402/tellusa.v52i2. 12259.

Rieck, J. K., C. W. Böning, and R. J. Greatbatch, 2018: Decadal variability of eddy kinetic energy in the South Pacific subtropical countercurrent in an ocean general circulation model. J. Phys. Oceanogr., 48, 757-771, https://doi.org/10.1175/JPOD-17-0173.1.

Schneider, N., and B. D. Cornuelle, 2005: The forcing of the Pacific decadal oscillation. J. Climate, 18, 4355-4373, https://doi.org/ 10.1175/JCLI3527.1.

Shakun, J. D., and J. Shaman, 2009: Tropical origins of North and South Pacific decadal variability. Geophys. Res. Lett., 36, L19711, https://doi.org/10.1029/2009GL040313.

Sloyan, B. M., and T. J. O'Kane, 2015: Drivers of decadal variability in the Tasman Sea. J. Geophys. Res. Oceans, 120, 3193 3210, https://doi.org/10.1002/2014JC010550.

Travis, S., and B. Qiu, 2017: Decadal variability in the South Pacific Subtropical Countercurrent and regional mesoscale eddy 
activity. J. Phys. Oceanogr., 47, 499-512, https://doi.org/ 10.1175/JPO-D-16-0217.1.

Trenberth, K. E., and J. W. Hurrell, 1994: Decadal atmosphereocean variations in the Pacific. Climate Dyn., 9, 303-319, https://doi.org/10.1007/BF00204745.

White, W. B., Y. M. Tourre, M. Barlow, and M. Dettinger, 2003: A delayed action oscillator shared by biennial, interannual, and decadal signals in the Pacific Basin. J. Geophys. Res., 108, 3070, https://doi.org/10.1029/2002JC001490.
Yang, S. C., E. Kalnay, M. Cai, and M. M. Rienecker, 2008: Bred vectors and tropical Pacific forecast errors in the NASA coupled general circulation model. Mon. Wea. Rev., 136, 13051326, https://doi.org/10.1175/2007MWR2118.1.

Ying, K., C. S. Frederiksen, X. Zheng, J. Lou, and T. Zhao, 2018: Variability and predictability of decadal mean temperature and precipitation over China in the CCSM4 last millennium simulation. Climate Dyn., 51, 2989-3008, https://doi.org/ 10.1007/s00382-017-4060-8. 